\title{
Fuga dalla purezza, giuridicità delle pretese e radici individuali della produzione giuridica nel pensiero di Bruno Leoni
}

\section{Daniele Bertolini}

(di prossima pubblicazione come saggio introduttivo al volume IV delle Opere complete di Bruno Leoni, Torino, IBL, 2020)

\author{
«...il formalismo giuridico si è \\ dimostrato un surrogato del tutto \\ insoddisfacente del diritto naturale, \\ soprattutto, credo, perché nella vita \\ giuridica ordinaria nessuno potrebbe \\ contentarsi di pure 'forme', più di quanto \\ possa contentarsi di fantasmi in amore o di \\ semplici odori a tavola» \\ Bruno Leoni, 1957 \\ "...il processo giuridico risale \\ sempre alla pretesa individuale. Gli \\ individui creano il diritto, nella misura in \\ cui avanzano pretese che hanno successo» \\ Bruno Leoni, 1964
}

Sommario: I. Contenuti 1. Premessa. - 2. Critica del positivismo giuridico. - 2.1. Critica della dottrina kelseniana del diritto. 2.2. Critica delle teorie "pure" del diritto. - 3. Teoria della pretesa. - 3.1. Il minimo significato comune del termine diritto. - 3.2. La definizione di pretesa. - 3.3. La giuridicità delle pretese.3.4. Lo scambio di pretese. - 3.5. Pretesa e coercizione. - 4. Teoria delle fonti del diritto - 4.1. La concezione leoniana delle fonti di produzione del diritto. - 4.2. Critica dei processi istituzionali di produzione del diritto. - II. BILANCIO CRITICO - 5. Fecondità teorica dell'impostazione leoniana. - 5.1. L'epistemologia giuridica leoniana. - 5.2. Giusnaturalismo empirista. - 5.3. Il diritto inteso come ordine spontaneo senza costrizione. -6 . Problemi irrisolti della teoria leoniana del diritto e future linee di ricerca. - 6.1. Ambiguità concettuale del giusnaturalismo empirico leoniano: l'obiezione della fallacia naturalistica. - 6.2. Debolezza esplicativa della teoria della pretesa e conseguente indebolimento della teoria normativa delle fonti. - 6.3. Il mancato confronto tra coercizione legale e coercizione privata.

\section{1.}

Sono raccolti in questo volume gli scritti di Bruno Leoni dedicati ai temi della teoria generale del diritto. ${ }^{1}$ La preoccupazione costante e centrale sottesa all'opera leoniana (che

\footnotetext{
${ }^{1}$ La teoria generale del diritto di Bruno Leoni è stata oggetto di un fecondo dibattitto da parte di studiosi sia italiani che stranieri. Senza pretesa di esaustività, s'indicano qui di seguito alcuni dei contributi maggiormente significativi: Juan Marcos de La Fuente, "Il diritto come pretesa e i rapporti tra diritto e politica", Rivista internazionale di filosofia del diritto, XXXVIII, 1961; Mario Stoppino, "L'individualismo integrale di Bruno Leoni", in Bruno Leoni, Scritti di scienza politica e di teoria del diritto, Milano, Giuffrè, 1980; AA. VV., "Il pensiero politico e giuridico di Bruno Leoni", Il Politico, XLVII, n. 1, 1982 (interventi di Norberto Bobbio, Antonio Febbrajo, Giacomo Gavazzi, Enrico Robilant, Uberto Scarpelli, Giuliano Urbano e Mario Stoppino); Peter H. Aranson, "Bruno Leoni in Retrospect", Harvard Journal of Law and Public Policy, XI, n. 3, 1988; Leonard Liggio - Tom Palmer, “A Comment on Professor Aranson's
} 
copre gli ambiti del diritto, della politica e della metodologia delle scienze sociali) è certamente quella di promuovere un sistema teorico e filosofico capace di spiegare, salvaguardare e promuovere l'ideale di libertà individuale. Sul terreno specifico della teoria generale del diritto, tale preoccupazione si declina in uno sforzo teso a elaborare una teoria della "giuridicità" che radichi l'essenza del diritto nei comportamenti e convincimenti generalmente diffusi tra $i$ singoli individui che agiscono sul piano giuridico in un dato ambito storico e sociale. Tale è il nucleo centrale e tema ricorrente negli scritti di Leoni dedicati alla teoria generale del diritto. Al fondo di tale preoccupazione non v'è un'esigenza puramente teoretica o speculativa, ma un profondo e genuino slancio ideale e politico. Ove la giuridicità sia radicata nei comportamenti e convincimenti generalmente diffusi tra singoli individui appartenenti a una data comunità e in un dato contesto storico, la distanza tra produttori e destinatari del diritto si riduce sin quasi, almeno idealmente, a dissolversi. Si realizza in tal modo la più potente ed efficace difesa della libertà individuale contro l'avvento e gli abusi di sistemi dispotici di governo. In estrema sintesi, nella riflessione giusfilosofica di Leoni la libertà individuale è coessenziale al radicarsi della produzione giuridica nell'azione e nei convincimenti dei singoli individui che operano sul piano giuridico.

Viene così a manifestarsi negli scritti giuridici leoniani un nesso profondo tra lo sforzo teorico - teso a cogliere l'essenza del fenomeno giuridico - e una viva tensione morale -

Article", Harvard Journal in Law \& Public Policy, 11, n. 3, 1988; Antonio Febbrajo, "Diritto ed economia nel pensiero di Bruno Leoni”, Sociologia del diritto, nn. 1-2, 1990, pp. 133-153; Raimondo Cubeddu, "Il liberalismo di Bruno Leoni", in La libertà e la legge, Macerata, Liberlibri, 1995; Mauro Barberis, "Diritto e legislazione. Rileggendo Leoni”, Rivista Internazionale di Filosofia del diritto, aprile/giugno, IV, LXXIII, 1996, p. 245; Mario Stoppino, "Introduzione" a Bruno Leoni, Le pretese e i poteri: le radici individuali del diritto e della politica, Milano, Società aperta, 1997; Maria Chiara Pievatolo, "Poteri informali: la libertà individuale fra spontaneità e artificio", Ragion pratica, n. 10, 1998; Fabio Massimo Nicosia, "L'anarchismo giuridico di Bruno Leoni", Materiali per una storia della cultura giuridica, 30, n. 1, 2000, pp. 153-170; Stefania Mazzone, "Dallo scambio delle pretese alla sovranità del consumatore. Diritto, poteri e mercato nell'individualismo di Bruno Leoni”, Materiali per una storia della cultura giuridica, 31, n. 2, 2001, pp. 423-440; Mauro Barberis, "La teoria del diritto di Bruno Leoni”, Quaderni di scienza politica, 2, 2003, pp. 263-284; Carlo Lottieri, "Introduzione” a Bruno Leoni, Lezioni di filosofia del diritto, Soveria Mannelli, Rubbettino, 2003; Antonio Masala, Il liberalismo di Bruno Leoni, Soveria Mannelli, Rubbettino, 2003; Silvia Menocci, L'antiformalismo di Bruno Leoni nei suoi rapporti con le correnti del realismo giuridico, Università degli Studi di Siena, Dipartimento di Scienze Storiche, Giuridiche, Politiche e Sociali, 2003; Emma Baglioni, L'individuo e lo scambio. Teoria ed etica dell'ordine spontaneo nell'individualismo di Bruno Leoni, Napoli, ESI, 2004; Mauro Barberis, "Introduzione" a Bruno Leoni, Il diritto come pretesa, Macerata, Liberilibri, 2004; Alberto Febbrajo, "Postfazione" a Bruno Leoni, Il diritto come pretesa, Macerata, Liberilibri, 2004; Carlo Lottieri, Le ragioni del diritto. Libertà individuale e ordine giuridico nel pensiero di Bruno Leoni, Soveria Mannelli, Rubbettino, 2006, pp. 262-272; Antonio Favaro, Bruno Leoni. Dell'irrazionalità della legge per la spontaneità dell'ordinamento, Napoli, ESI, 2009; Adriano Gianturco Gulisano, "La 'teoria empirica' di Bruno Leoni. La centralità dell'approccio metodologico", Biblioteca della libertà, XLVI, n. 200, 2011; Carlo Lottieri, "Alle origini della teoria del diritto come pretesa individuale. Da Widar Cesarini Sforza a Bruno Leoni”, Materiali per una storia della cultura giuridica, 41, n. 1, 2011, pp. 63-90; Nicolò, Zanon "Tra giurisdizione e legislazione. Leggendo 'La libertà e la legge' di Bruno Leoni”, Quaderni costituzionali, 38, n. 1, 2018, pp. 253-266; Carlo Lottieri, "Exchanges, Claims, and Powers: About Bruno Leoni's Social Theory", https://oll.libertyfund.org/pages/lm-leoni, 2019 (commenti di Peter T. Leeson, Edward Peter Stringham e Boudewijn Bouckaert). Mi sia infine consentito di rinviare a Daniele Bertolini, "The Theory of Law as Claim and the Inquiry into the Sources of Law: Bruno Leoni in Prospect”, Southern California Interdisciplinary Law Journal, 24, 2014, p. 561. 
tesa alla salvaguardia e promozione della libertà individuale. Tale nesso si traduce, innanzitutto, nella precisa individuazione di taluni, costanti, referenti polemici. Tra essi figurano innanzitutto il positivismo giuridico e, in particolare, la dottrina kelseniana del diritto, che del positivismo giuridico rappresentava, ai tempi in cui Leoni scriveva, l'espressione più matura, capace di influire maggiormente sulla cultura giuridica italiana ed europea. Un secondo obiettivo polemico è dato dalle concezioni organicistiche della società, tese a identificare la società come un tutto organico e conseguentemente a cercare il fondamento delle proposizioni riguardanti i fenomeni sociali nelle volizioni e azioni di soggetti e organismi collettivi. A tali concezioni Leoni contrappone un rigoroso e intransigente individualismo metodologico e teorico teso a spiegare $\mathrm{i}$ fenomeni sociali, facendo riferimento alle volizioni e azioni di singoli individui. ${ }^{2}$ Infine, la polemica antipositivista sul piano teorico e quella antiorganicistica sul piano metodologico conducono la riflessione leoniana a identificare un terzo e cruciale obiettivo polemico, questa volta sul piano della riflessione istituzionale: il monopolio della legislazione nel sistema delle fonti del diritto. È bene enfatizzare sin da subito, come si avrà cura di dimostrare più accuratamente nel seguito di questo saggio introduttivo, che la teoria individualista del diritto, elaborata negli scritti contenuti in questo volume, fornisce le basi teoriche alla celebre critica leoaniana della legislazione sviluppata in La libertà e il diritto. ${ }^{3}$ Da questo punto di vista, si può dire, senza tema di smentita, che gli scritti raccolti in questo volume racchiudano il nucleo teorico più prezioso e originale dell'impostazione giusfilosofica leoniana.

Ma la riflessione di Leoni sul diritto non si esaurisce nella pur significativa identificazione di obiettivi polemici. Nell'attaccare criticamente positivismo, organicismo e monopolio legislativo, Leoni traccia i contorni di una proposta filosofica alternativa, originalissima e, per alcuni versi, anticipatrice di taluni indirizzi teorici e metodologici poi affermatisi con un certo seguito nell'ambito dell'economia e del diritto. ${ }^{4}$ Come non sfuggirà all'attento lettore, negli scritti leoniani, all'analisi critica di ciascun referente polemico corrisponde sempre l'indicazione delle linee essenziali di una proposta teorica

\footnotetext{
${ }^{2} \mathrm{Nel}$ definire l'orientamento di fondo dell'opera di Leoni, Mario Stoppino è ricorso alla formula - oramai divenuta celebre tra gli studiosi dell'opera leoniana - dell'"individualismo integrale"; si veda, Mario Stoppino, "L'individualismo integrale di Bruno Leoni", in Bruno Leoni, Scritti di scienza politica e di teoria del diritto, Milano, Giuffrè, 1980. Cfr. anche Mario Stoppino, "La grande dicotomia diritto privato diritto pubblico e il pensiero di Bruno Leoni", Il Politico, XLVII, n. 1, 1982, p. 122. Con la definizione d'individualismo integrale si pone l'enfasi sul fatto che l'orientamento di Leoni comprende tanto l'individualismo metodologico (che radica le azioni sociali nelle azioni e volizioni individuali negando che entità collettive possano considerarsi soggetti capaci di sentimenti, volizioni e azioni) quanto l'individualismo teorico (secondo cui il concetto di "individui" costituisce la nozione teorica fondamentale per l'elaborazione di una teoria esplicativa della società). In senso parzialmente critico verso tale definizione, si veda Alberto Febbrajo, "L'influenza di Max Weber sulla concezione leoniana del diritto come pretesa", Il Politico, XLVII, n. 1, 1982, pp. 164-165.

${ }^{3}$ Volume II di quest'opera.

${ }^{4}$ Sull'influenza esercitata dal pensiero di Leoni sulla successiva riflessione giuridico-economica, si veda Peter H. Aranson, "Bruno Leoni in Retrospect", Harvard Journal of Law \& Public Policy, 3, 1988, pp. 661-711 e, più di recente, Tom G. Palmer, "Bruno Leoni's Enduring Influence on Legal Thought: A Translantic Perspective", in Roberta Adelaide Modugno - Diana Thermes (a cura di), Bruno Leoni. Per un liberalismo integrale, Soveria Mannelli, Rubbettino, 2017.
} 
alternativa, con la quale Leoni si propone di superare in modo assai originale alcuni dei più convenzionali schemi concettuali e orizzonti teorici.

Nelle pagine che seguono si proverà ad articolare i principali capisaldi polemici e $\mathrm{i}$ più importanti nodi teorici della riflessione leoniana sui temi della teoria generale del diritto. La discussione si articola in due momenti. Si tenta innanzitutto di riassumere e precisare le principali tesi leoniane facendo stretto riferimento agli scritti qui antologizzati (sezioni 2-4); in seguito, si tenta di fornire un bilancio critico dell'impostazione giusfilosofica leoniana enfatizzandone gli elementi di maggiore originalità e fecondità teorica e individuandone i principali limiti e nodi irrisolti (sezioni 5-6). La discussione è organizzata per sezioni come segue: la seconda sezione riassume gli aspetti tecnici della critica leoniana del normativismo kelseniano e le ragioni dell'insoddisfazione di Leoni per le teorie "pure" del diritto; la terza sezione si concentra sulla teoria della pretesa, con cui Leoni si propone di superare i vizi teorici del normativismo di matrice kelseniana; la quarta sezione illustra il collegamento tra la teoria della pretesa e quella delle fonti di produzione giuridica; la quinta e la sesta sezione tentano un bilancio critico dell'impostazione giusfilosofica leoniana esaminando, rispettivamente, gli insegnamenti che possono trarsi dagli scritti sulla teoria della pretesa e $\mathrm{i}$ punti di maggiore problematicità o debolezza teorica di tale impostazione.

\section{2.}

La riflessione giusfilosofica di Leoni nasce e si sviluppa sul terreno di una critica radicale alla dottrina kelseniana del diritto. ${ }^{5}$ Pertanto, proprio l'analisi dell'antikelsenismo leoniano consente di individuare alcuni dei più importanti capisaldi metodologici che caratterizzano l'approccio di Leoni alla teoria generale del diritto. È opportuno procedere affrontando, nell'ordine, tre ordini di considerazioni: 1) un esame riassuntivo dei principali tratti teorici del normativismo kelseniano; 2) le critiche puntuali che Leoni indirizza alla dottrina del diritto di Kelsen; 3) la critica metodologica che Leoni indirizza, in generale, alle concezioni "puriste" o "logico-formali" del diritto.

2.1. La dottrina kelseniana del diritto si ricollega da un lato al positivismo giuridico e dall'altro al neokantismo filosofico. In primo luogo, Kelsen si propone di conseguire una conoscenza genuinamente "scientifica" del diritto, in coerenza con un impianto concettuale di stampo tipicamente positivista. In questa prospettiva, la scientificità del sapere giuridico può conseguirsi solo distinguendo e mantenendo rigorosamente separati il punto di vista esplicativo/causale da quello normativo/formale. La centralità

\footnotetext{
${ }^{5}$ Sull'antikelsenismo leoniano, si vedano: Norberto Bobbio, "Bruno Leoni di fronte a Weber e a Kelsen", Il Politico, XLVII, n. 1, 1982, pp. 131-136; Mauro Barberis, "La teoria del diritto di Bruno Leoni", pp. 263284; Carlo Lottieri, Le ragioni del diritto. Libertà individuale e ordine giuridico nel pensiero di Bruno Leoni, pp. 262-272; Francesco Riccobono, "Tre episodi dell'antikelsensimo di Bruno Leoni”, in Roberta Adelaide Modugno - Diana Thermes (a cura di), Bruno Leoni. Per un liberalismo integrale, pp. 65-79; Adolfo Noto, "Critica del normativismo e limiti della democrazia nell'individualismo di Bruno Leoni", in Roberta Adelaide Modugno - Diana Thermes (a cura di), Bruno Leoni. Per un liberalismo integrale, pp. 150-165.
} 
metodologica di tale distinzione è il riflesso obbligato della duplice natura, fattuale e normativa, del diritto. Il diritto può essere indagato come fatto - cioè come insieme di comportamenti dei soggetti concreti che producono, interpretano, osservano o violano le norme giuridiche - o come norma - cioè come insieme di comandi e divieti che esprimono obblighi a carico dei destinatari delle norme giuridiche. Secondo Kelsen, il diritto inteso come fatto è oggetto di studio della sociologia e della psicologia sociale, le quali elaborano spiegazioni causali dei comportamenti sottesi al fenomeno giuridico. Il diritto inteso come norma è invece oggetto di studio della scienza normativa, il cui compito è di comprendere la struttura logico-formale delle norme giuridiche, a prescindere da qualunque elemento contenutistico e psicologico. Secondo Kelsen, dunque, il prerequisito di una conoscenza genuinamente scientifica del diritto è la netta separazione tra questi due ambiti d'indagine. La conoscenza del diritto è scientifica se è "pura", se si concentra, cioè, sulla struttura logico-formale delle norme giuridiche, indipendentemente da ogni considerazione circa la realtà dei comportamenti concreti e dei processi psicologogici di volontà dei produttori e dei destinatari di norme.

Kelsen persegue l'obiettivo di una conoscenza "pura" del diritto mediante l'impiego di un'impostazione epistemologica di tipo neokantiano. ${ }^{6}$ Come già anticipato, Kelsen intende il diritto come un fenomeno essenzialmente normativo. La norma è una proposizione linguistica esprimente un Sollen ("dover essere"); come tale, essa non esprime un collegamento tra una causa e il suo effetto, quanto piuttosto, e innanzitutto, un collegamento concettuale tra fattispecie astratte come, ad esempio, il collegamento tra la fattispecie dell'illecito e quella della sanzione. Il diritto si presenta pertanto come un insieme di concetti intellettivi puri, di forme condizionanti del pensiero, mediante le quali gli uomini "imputano" determinati effetti a determinati eventi. In questa prospettiva, la norma giuridica esprime una legge di collegamento ("imputazione") che è propria del diritto e non è assimilabile ai collegamenti causali oggetto di studio da parte delle scienze naturali ("causalità"). ${ }^{7} \mathrm{Ne}$ deriva che essa non possa utilizzare il metodo d'indagine proprio delle scienze naturali, ma necessiti di un metodo scientifico autonomo e commisurato alla specificità del proprio oggetto d'indagine. Tale è il metodo trascendentale kantiano che mira a identificare gli elementi a priori della conoscenza.

In tale impostazione, la distinzione tra il mondo del Sein ("essere") e quello del Sollen assume un ruolo centrale. Nel sistema teorico kelseniano, il diritto come oggetto di conoscenza scientifica appartiene alla sfera del Sein mentre il Sollen rimane estraneo alla sfera del diritto. La dottrina kelseniana del diritto è "pura" nel senso kantiano del termine - essa mira a identificare gli elementi a priori della conoscenza giuridica, destinati a essere applicati a una varietà di contenuti storici.

Chiariti i presupposti filosofici dell'epistemologia giuridica kelseniana, è ora opportuno richiamare brevemente i punti fondamentali della dottrina pura del diritto, sui cui si

\footnotetext{
${ }^{6}$ Sulle origini neokantiane della teoria pura del diritto, si veda: Mario G. Losano, "Saggio Introduttivo", in Hans Kelsen, La dottrina pura del diritto, Torino, Einaudi, 1960; Stanley L. Paulson, "The Neo-Kantian Dimension of Kelsen's Pure Theory of Law", Oxford Journal of Legal Studies, 12, n. 3, 1992, pp. 311-332; Pierluigi Chiassoni, Da Bentham a Kelsen, Torino, Giappichelli, 2016, pp. 308-337.

${ }^{7}$ Cfr. Hans Kelsen, "Causalità e imputazione", in Lineamenti di dottrina pura del diritto, Einaudi, Torino, 2000, pp. 207-227.
} 
appunteranno, come vedremo, le critiche di Leoni. Come chiarito in precedenza, l'essenza del diritto risiede per Kelsen nella "norma", intesa come una proposizione linguistica esprimente un "dover essere". Caratteristica principale della norma giuridica è quella di prescrivere un "obbligo" a carico dei suoi destinatari. Tale obbligo, a sua volta, origina da un "comando" emanato da una "autorità" giuridica legittima. La legittimità dell'autorità che emana norme è stabilita da norme gerarchicamente superiori che stabiliscono le condizioni formali di legittimità della produzione giuridica delle norme di rango inferiore. La validità giuridica viene dunque a coincidere con il rispetto delle condizioni procedurali - delle forme della produzione giuridica - stabilite da norme gerarchicamente superiori. È estranea alla "validità" della norma ogni considerazione concernente la dimensione empirica dell'"efficacia", intesa come conformità del comportamento dei destinatari della norma al comando in essa contenuta. L'efficacia della singola norma appartiene al mondo del Sein e come tale è estranea alla validità che appartiene alla sfera del Sollen.

Nell'ottica kelseniana, tesa a rappresentare la sfera della normatività in modo indipendente dai comportamenti e dalle intenzioni degli individui che agiscono sul piano giuridico, il comando che la norma esprime è inteso come un "comando depsicologizzato", ossia come una proposizione imperativa non riferibile al fatto psicologico concreto del comando. Poiché ogni riferimento al contenuto psicologico del comando contraddirebbe l'assunto di base secondo il quale il diritto appartiene al mondo del Sollen, Kelsen elabora la nozione di "comando depsicologizzato" al fine di separare il comando espresso dalla norma dagli atteggiamenti psicologici degli individui che impartisco e ricevono il comando.

Infine, poiché la validità di una norma è fatta dipendere dalla validità di norme gerarchicamente superiori, essa porta a concepire l'ordinamento giuridico alla stregua di una struttura piramidale organizzata su livelli di norme gerarchicamente ordinati. Kelsen fa dipendere la validità dell'intero ordinamento giuridico da una Grundnorm (norma fondamentale), la cui funzione è quella di conferire legittimità agli atti del legislatore originario e in tale modo garantire legittimità a tutta la produzione giuridica. Non v'è chi non veda come tale impostazione teorica finisca per legittimare una concezione (almeno in una certa misura) centralizzata della produzione giuridica. Non stupisce dunque che la concezione kelseniana dello Stato sia imperniata sull'identità tra Stato e ordinamento giuridico.

2.2. La critica leoniana alla dottrina del diritto di Kelsen è contenuta, in particolare, nei due saggi intitolati Oscurità e incongruenze nella dottrina kelseniana del diritto e Il concetto di stato nella teoria kelseniana, apparsi rispettivamente nel 1960 e nel $1961 .^{8}$

In Oscurità e incongruenze Leoni individua con precisione i principali ostacoli che impediscono alla teoria kelseniana di fornire una quadro teorico coerente e soddisfacente della natura del diritto. Leoni contesta alla radice l'adeguatezza della distinzione

\footnotetext{
${ }^{8}$ Leoni articola ulteriormente la sua critica al normativismo kelseniano in Bruno Leoni, Lezioni di Filosofia del diritto, Soveria Mannelli, Rubbettino, 2003 e in Appunti dal corso di Filosofia del diritto. Anno Accademico 1965-1966, redatti da Stefano Lenghi, in Il Diritto come Pretesa, Macerata, Liberlibri, 2004.
} 
kelseniana tra Sein e Sollen come premessa fondativa di una teoria generale del diritto. Il filosofo torinese nega sia possibile considerare le norme giuridiche come espressione di un Sollen separato dal Sein relegando con ciò l'essenza del diritto al mondo del puro dover essere. Leoni osserva che, in fondo, nonostante gli sforzi compiuti da Kelsen per separare il Sein dal Sollen, nella teoria kelseniana «il Sollen in cui si manifestano le norme finisce per diventare un Sein, ossia un qualche aspetto della realtà». ${ }^{9}$

L'insostenibità teorica della distinzione tra Sein e Sollen si riflette nelle gravi difficoltà definitorie sollevate dal concetto di norma come "comando depsicologizzato". ${ }^{10}$ Tale concetto, come accennato in precedenza, è il frutto dello sforzo kelseniano di elaborare una dottrina pura del diritto, scevra da ogni contaminazione di natura psicologica, come sarebbe quella insita nella nozione ordinaria di comando. Leoni osserva che non è affatto chiaro cosa sia un comando depsicologizzato. Ancor peggio, qualora si tenti di recuperare un significato plausibile a tale espressione, si finisce irrimediabilmente col ritrovarvi quel Sein che la teoria kesleniana vorrebbe separato completamente dal Sollen. Potrebbe dirsi, per esempio, che l'espressione comando depsicologizzato si riferisca all'idea di un "significato pensato" autonomo dalle persone destinatarie del comando. Tuttavia, occorrerebbe riconoscere, in tal caso, che il significato pensato, da un lato, e l'individuo pensante quel significato, dall'altro, non stanno tra loro in una relazione di separatezza del tipo di quella che intercorre (nella teoria di Kelsen) tra il Sein e il Sollen. Il significato pensato di "comando" sarebbe autonomo dalle persone che lo pensano solo nella stessa misura in cui una qualsiasi astrazione può considerarsi autonoma dalle persone che compiono quell'astrazione. Il comando depsicologizzato, cioè, non è distaccato né distaccabile dalla psicologia degli individui che "intendono" quel significato. Ma se cosi è, conclude Leoni, «è difficile dire che il 'comando depsicologizzato' non abbia relazioni col mondo proibito del Sein, dal momento che esso ci appare, in questa ipotesi, come una semplice astrazione relativa a una realtà psicologica». ${ }^{11}$

La distinzione tra Sein e Sollen manifesta la sua inadeguatezza analitica anche quando si pretenda di fondare su di essa la fondamentale distinzione tra "validità" ed "efficacia" della norma giuridica. Nel sistema di Kelsen, la "validità" è caratteristica fondamentale della norma giuridica e pertiene esclusivamente al mondo del Sollen; l'efficacia, di contro, pertiene al mondo del Sein, giacché essa riguarda i comportamenti effettivi dei destinatari delle norme. Tuttavia, qualora si esamini la definizione di validità, ci si avvede dell'impossibilità di mantenere tale concetto sul solo piano del Sollen distaccato da quello del Sein. Kelsen definisce la validità come la specifica forma di "esistenza delle norme". E tuttavia, Leoni osserva, «il termine "esistenza" sembra avere più di un rapporto con quel famoso Sein al quale le norme come tali dovrebbero - per il Kelsen - appartenere». ${ }^{12}$ Ancora, nel definire la validità Kelsen fa riferimento alla "forza vincolante" delle norme per i loro destinatari. Tale espressione, nella sua più naturale interpretazione,

\footnotetext{
${ }^{9}$ Oscurità e incongruenze, p. 303.

${ }^{10}$ Riccobono afferma: «Leoni è uno dei pochi autori a rilevare la contraddittorietà e la stravaganza della definizione kelseniana della norma come un "commando depsicologizzato"»; Francesco Riccobono, "Tre episodi dell'antikelsensimo di Bruno Leoni", in Roberta Adelaide Modugno - Diana Thermes (a cura di), Bruno Leoni. Per un liberalismo integrale, pp. 65-79, in particolare p. 77.

${ }^{11}$ Oscurità e incongruenze, pp. 305-306.

${ }^{12}$ Oscurità e incongruenze, p. 306.
} 
sembrerebbe riferirsi al «fatto che determinate persone si sentano obbligate a obbedire alla norma». ${ }^{13}$ Ma l'evento psicologico del sentirsi vincolati da una norma afferisce all'efficacia, e dunque «appartiene a quel mondo del Sein che nella dottrina si vuol mantenere rigorosamente distinto dal mondo del Sollen cui la norma appartiene». ${ }^{14}$ Dopo avere esaminato i vari possibili significati di validità, Leoni afferma che «tutte le interpretazioni [...] escogitate per dare un senso alla distinzione tra validità ed efficacia della norma ci rinviano in ultima analisi al concetto di "efficacia"». ${ }^{15}$

Per salvare la distinzione tra validità ed efficacia Kelsen afferma che la validità della singola norma non dipende direttamente dalla sua efficacia, ma da quella dell'intero ordinamento giuridico cui essa appartiene. In tal senso, la validità di una norma giuridica non presupporrebbe la sua osservanza da parte dei destinatari, ma dipenderebbe piuttosto dal fatto che i destinatari accettino l'intero ordinamento giuridico cui la norma appartiene. Leoni osserva che ciò condurrebbe la logica kelseniana a un possibile paradosso: «[P]otremmo immaginare per assurdo un ordine giuridico che, considerato nel suo complesso [...] venisse accettato da ognuno, pur non essendo, in ipotesi, nessuna singola norma dell'ordine, accettata da alcuno». ${ }^{16}$

Che la duplice distinzione tra Sein e Sollen e tra "validità" ed "efficacia" sia concettualmente vacillante trova una conferma ulteriore nelle difficoltà teoriche associate al concetto di "norma base" (o "fondamentale"), termine con cui Kelsen designa la norma, come abbiamo visto, che conferisce legittimità all'intero ordinamento giuridico. Secondo Leoni, il concetto di norma base rappresenta una contraddizione in termini. Per essere "valida", la "norma base" dovrebbe perdere il suo carattere basilare - non si vede, infatti, come potrebbe essere valida una norma che in quanto basilare non sia emanata da un'autorità definita legittima da una norma superiore; d'altro canto, per essere "basilare", la norma fondamentale non può mantenere il suo carattere di norma giuridica "valida", poiché la validità della norma giuridica dipende da norme superiori che ne legittimino la creazione. Pertanto, nel sistema kelseniano non è dato ritrovare un fondamento logicamente saldo della validità dell'ordinamento giuridico. $\mathrm{O}$ la norma base è norma al pari di tutte le altre norme - ma in tal caso non si capisce sul piano logico come possa mantenersi il suo carattere "basilare" - o essa non è in realtà una norma giuridica - ma allora essa appartiene al mondo del Sein e ciò contraddice la pretesa di "purezza" del Sollen kelseniano. ${ }^{17}$

Il formalismo proprio della dottrina kelseniana si rivela incapace di definire l'oggetto della scienza giuridica. Kelsen definisce l'oggetto della teoria del diritto come lo studio

\footnotetext{
${ }^{13}$ Oscurità e incongruenze, p. 306.

${ }^{14}$ Oscurità e incongruenze, pp. 306-307.

${ }^{15}$ Oscurità e incongruenze, p. 309.

${ }^{16}$ Oscurità e incongruenze, p. 310.

${ }^{17} \mathrm{Su}$ questo punto, Leoni anticipa parte della critica che Bulygin muoverà più tardi al sistema kelseniano. Bulygin individua una contraddizione, all'interno del sistema kelseniano, tra l'assunto positivistico - che si traduce nel rigetto di ogni pretesa volta a fondare la validità delle norme su basi esterne all'ordinamento positivo - e una concezione normativa della validità giuridica - che, facendo dipendere quest'ultima dalla forza vincolante di una norma, implica un problema di regresso ad infinitum che solo l'introduzione nel sistema di un qualche fondamento esterno all'ordinamento può risolvere; Eugenio Bulygin, "An Antinomy in Kelsen's Pure Theory of Law", Ratio Iuris, 3, n. 1, 1990, pp. 29-45.
} 
del "diritto positivo", il quale consiste dell'insieme di norme create da autorità legittime. Tale definizione si rivela incapace di fornire un valido criterio distintivo tra diritto "positivo" e "non positivo", poiché non è chiaro cosa debba intendersi, nel sistema kelseniano, per "creazione" della norma. Osserva Leoni che per rimanere coerenti con la dottrina "pura" della norma, occorrerebbe "scartare, come non pertinenti al mondo del Sollen, tutte le interpretazioni del concetto di "creazione" che si richiamano al mondo dei fatti». ${ }^{18} \mathrm{Ma}$ la dottrina kelseniana non offre criteri di natura concettuale che consentano di scegliere tra i vari possibili concetti di diritto. Quando parla di diritto positivo in termini di teoria pura, Kelsen ha in mente probabilmente l'insieme di regole di condotta poste, o imposte, dai detentori del potere politico in un certo ambito storico. Tuttavia il «fatto che un certo insieme di regole di condotta viene posto da taluni ad altri in un certo tempo e in un certo luogo della storia» non è ragione sufficiente «per scegliere, tra tutti i possibili concetti di "diritto", quello corrispondente alle regole di condotta "poste" dai detentori del potere politico-militare in un determinato ambito storico» ${ }^{19}$. Poiché in ogni ambito storico «ci si trova di fronte non a uno ma a più ordinamenti, spesso contemporaneamente efficaci per le stesse persone», ${ }^{20}$ per definire l'oggetto di analisi della teoria generale del diritto occorrono delle ragioni concettuali che consentano di definire la giuridicità sul piano teorico. Beninteso, Leoni riconosce che la nozione di "diritto positivo" possa svolgere, e anzi sicuramente svolga, un'utile funzione pratica sul piano della dogmatica giuridica (esso è utile, ad esempio, per facilitare al giudice il compito di individuare il fondamento della sua decisione o alla parte in causa il compito di identificare il fondamento della propria azione o difesa processuale). Ma qualora la riflessione si muova dal piano della dogmatica a quello della teoria del diritto, il concetto di diritto positivo si rivela di scarso valore teoretico ove esso non sia inserito nel contesto di una teoria compiutamente esplicativa dei processi concreti di formazione del diritto.

La critica del normativismo elaborata in Oscurità e incongruenze costituisce la premessa logica della critica che Leoni muove alla concezione kelseniana dello Stato. Nello scritto intitolato Il concetto di "Stato" nella teoria kelseniana, Leoni critica la tesi dell'identità tra Stato e ordinamento giuridico. Leoni rileva che nel sistema kelseniano l'ordinamento giuridico debba intendersi come un insieme di norme, di comandi depsicologizzati, cioè, in definitiva, un insieme di proposizioni prescrittive «staccate dalle menti dei soggetti umani». ${ }^{21}$ Sulla base di tale premessa, la tesi dell'identità tra Stato e ordinamento giuridico porta a concepire il primo come un insieme di proposizioni linguistiche autonome e indipendenti dalle menti degli individui che pensano e agiscono avendo in mente il concetto di Stato. Ora, secondo Leoni, è assai dubbio che il tentativo kelseniano di mantenere le proposizioni di un ordinamento giuridico «in un intermondo nel quale nessun essere pensante e agente le riguardi o ne sia riguardato» possa essere in alcun modo utile per il teorico generale del diritto. ${ }^{22}$ Tale impostazione nominalistica non è in grado di spiegare «di dove quelle proposizioni provengono, chi le ha formulate, in quale

\footnotetext{
${ }^{18}$ Oscurità e incongruenze, p. 314.

${ }^{19}$ Oscurità e incongruenze, p. 318.

${ }^{20}$ Oscurità e incongruenze, p. 316 (corsivo dell'autore).

${ }^{21}$ Il concetto di "Stato" nella teoria kelseniana, p. 33.

${ }^{22}$ Il concetto di "Stato” nella teoria kelseniana, p. 35.
} 
ambito e per quale scopo», ${ }^{23}$ ne è in grado di spiegare «che cosa effettivamente accade in una comunità giuridica o politica concreta». ${ }^{24}$ Per Leoni, lo stato è «un complesso di relazioni di potere fra $i$ vari individui che compongono la comunità politica». ${ }^{25} \mathrm{Ne}$ deriva che per comprendere cosa sia lo Stato, come esso si formi e come esso si distingua da altre forme di potere non si possa prescindere dall'esame delle relazioni di potere che intercorrono tra gli individui. La riduzione kelseniana del concetto sociologico di Stato al concetto di ordinamento giuridico non consente al teorico del diritto di indagare e comprendere i rapporti tra gli individui concreti nei quali si identifica lo Stato.

In conclusione, alla luce delle obiezioni qui brevemente riassunte, la teoria kelseniana del diritto si presenta agli occhi di Leoni come un insieme di concetti analiticamente problematici, incapaci di cogliere l'essenza del fenomeno giuridico. L'insufficienza sul piano analitico della distinzione tra Sein e Sollen si riflette nell'oscuro concetto di comando depsicologizzato, nella difficoltà di separare la validità dall'efficacia, nell'ambiguità delle nozione di Grundnorm e nell'incapacità di definire l'oggetto stesso della teoria del diritto. Non è questa la sede per una compiuta analisi dei meriti e delle debolezze delle critiche leoniane all'impostazione kelseniana. ${ }^{26}$ Ciò che preme qui rilevare è che tali critiche indichino le caratteristiche che, secondo Leoni, una teoria del diritto deve possedere per superare i limiti del positivismo giuridico.

2.3. Le numerose obiezioni teoriche che Leoni muove alla teoria kelseniana del diritto discendono tutte, a ben vedere, da una radicale critica al "purismo giuridico", all'idea cioè che una teoria generale del diritto possa essere concepita come un sistema astratto di norme universalmente valide, senza riferimento al loro contenuto, e indipendentemente dalle azioni e convinzioni dei singoli individui che agiscono sul piano giuridico in un determinato ambito storico. Quest'aspetto è spiegato con chiarezza nello scritto intitolato Verso una nuova teoria pura del diritto, nel quale Leoni recensisce favorevolmente un saggio del suo allievo Alessandro Giuliani. Riassumendo e appoggiando le tesi del Giuliani, Leoni scrive: «...il purismo giuridico ha smarrito il senso dell'individualità delle azioni umane nelle quali si manifesta il diritto, ha sacrificato quindi il concetto di diritto soggettivo a quello di diritto oggettivo e ha sovrapposto arbitrariamente al concetto di azione giuridica del singolo il concetto di una «norma» astratta ed estrinseca, librata

\footnotetext{
${ }^{23}$ Il concetto di "Stato" nella teoria kelseniana, p. 35.

${ }^{24}$ Il concetto di "Stato" nella teoria kelseniana, p. 34 (corsivo dell'autore).

${ }^{25}$ Il concetto di "Stato" nella teoria kelseniana, p. 32 (corsivo dell'autore).

${ }^{26}$ Cfr. Mauro Barberis, "La teoria del diritto di Bruno Leoni", pp. 263-284 ove si afferma che Leoni cerca di accreditare la propria critica al normativismo kelseniano come una critica interna "senza mai fugare il sospetto, però, di avanzare una critica esterna, se non estrinseca» (p. 276). In un'analoga direzione sembra orientarsi Francesco Riccobono in Tre episodi dell'antikelsenismo di Bruno Leoni, in Roberta Adelaide Modugno - Diana Thermes (a cura di), Bruno Leoni. Per un liberalismo integrale, pp. 65-79, ove si afferma che «il dissidio tra Leoni e Kelsen [...] sia un dissidio tra punti di vista "ultimi". Da una parte, in Leoni, vi è l'idea che la ricchezza dei "convincimenti degli individui" appartenga immediatamente al campo del diritto [...]; dall'altra, in Kelsen, vi è l'idea che i convincimenti individuali siano, per loro natura valoriale, insondabili per una conoscenza scientifica e, quindi, da escludere in una considerazione scientifica del diritto che non voglia tramutarsi in una politica del diritto» (p. 78).
} 
per così dire a mezz'aria, senza rapporti con i singoli soggetti individuali delle azioni giuridiche». ${ }^{27}$

Il vizio metodologico della dottrina kelseniana del diritto non starebbe dunque nel "normativismo" di per sé, inteso come teorizzazione della norma giuridica, ma nel «normativismo concepito come un sistema chiuso e avulso dal complesso delle volizioni e delle azioni individuali» ${ }^{28}$. Tale ultima concezione - ammonisce Leoni - «presenta il duplice pericolo [...] di farci perdere di vista la realtà concreta del diritto e di favorire l'avvento di sistemi dispotici di governo». ${ }^{29}$ Emerge qui chiarissimo il nesso, segnalato in precedenza, tra opzione teorica e configurazione politico-istituzionale. Qualora il normativismo sia inteso come riduzione del diritto a norma e della norma a comando astratto dello Stato, esso finisce col favorire l'identificazione del diritto con la legge e della legge con la volontà di chi detiene il potere politico in un determinato momento storico. Il diritto finisce cioè per smarrire il suo essenziale collegamento - "genetico" prima ancora che logico - con le libere azioni e volizioni dei singoli individui che agiscono sul piano giuridico.

In Verso una nuova teoria pura del diritto, Leoni è attento a non sovrapporre concettualmente "purismo" e "normativismo". È la pretesa "purista" che esclude l'individualismo metodologico, non tanto lo sforzo, pienamente legittimo sul piano scientifico, di elaborare una teoria della norma. Leoni afferma: «il normativismo non esclude necessariamente l'individualismo metodologico, ma può considerarsi, a determinate condizioni, come un metodo complementare di esso, e quindi, nella sua sfera, utile, e anzi necessario, per la comprensione del mondo giuridico». ${ }^{30}$ Il vizio fondamentale della dottrina kelseniana non è il normativismo in sé considerato, ma il normativismo "purista", che cerca l'essenza delle norme al di fuori della sfera delle azioni e volizioni dei singoli individui. Tale normativismo contraddice l'individualismo metodologico ed è fonte tanto di distorsione analitica quanto d'inevitabili inadeguatezze istituzionali sul piano dell'organizzazione delle fonti del diritto.

Tali considerazioni metodologiche sono riprese e sviluppate nell'importante saggio intitolato A proposito della teoria del diritto e del positivismo giuridico, apparso nella rivista Il Politico nel 1966, nel quale Leoni delinea con chiarezza i tratti essenziali di una prospettiva metodologica alternativa alle teorie del diritto "pure" o "logico formali". Leoni afferma che una teoria generale del diritto non può limitarsi a studiare le condizioni logico-formali del discorso giuridico. Compito della teoria del diritto è quello di elaborare una teoria esplicativa dell'azione giuridica, che definisca in che cosa consista l'azione giuridica, ne spieghi il processo di verificazione, e identifichi le condizioni che ne determinano la maggiore o minore probabilità. Col termine "azione giuridica", come vedremo, Leoni intende fare riferimento alle pretese di ogni individuo e all'adeguamento di ogni individuo alle corrispondenti pretese di altri individui.

Insomma, la mossa teorica fondamentale e per molti versi metodologicamente rivoluzionaria che Leoni compie negli scritti di teoria generale del diritto è porre l'azione

\footnotetext{
${ }^{27}$ Verso una nuova teoria pura del diritto, p. 82.

${ }^{28}$ Verso una nuova teoria pura del diritto, p. 84.

${ }^{29}$ Verso una nuova teoria pura del diritto, p. 84.

${ }^{30}$ Verso una nuova teoria pura del diritto, p. 84.
} 
giuridica al centro della riflessione teorica, spostando l'attenzione dalle condizioni logico-formali del discorso giuridico alle condizioni empiriche di maggiore o minore probabilità dell'esercizio da parte di singoli individui di determinate pretese e dell'adeguamento altrui a tali pretese.

Questa nuova prospettiva teorica muta radicalmente il campo d'indagine rispetto a quanto accade nel normativismo purista. La teoria del diritto viene a occuparsi «[dell]'analisi delle relazioni, complesse e non sempre apparenti, che intercorrono tra tutti gli scopi da un lato, e tutti i mezzi dall'altro, nell'azione dell'operatore giuridico...». ${ }^{31}$ In tale contesto analitico, la duplice distinzione kelseniana tra Sein e Sollen e tra validità ed efficacia perde ogni rilevanza teorica. Anzi, essa diviene ostacolo che si frappone alla corretta comprensione del fenomeno giuridico. La norma giuridica non è più un comando "depsicologizzato" e non è più indagata al solo scopo di analizzarne la sola struttura formale in modo del tutto indipendente dall'osservazione empirica della realtà storica, psicologica e sociale da cui essa origina. Al contrario, la norma è concepita in termini empirici, con riferimento alle azioni dei singoli individui, agli scopi da essi perseguiti, e ai convincimenti che ne guidano l'azione. È nell'analisi di quelle azioni, quegli scopi e quei convincimenti che il teorico del diritto cerca una spiegazione del processo di produzione giuridica.

In sintesi, Leoni rovescia la prospettiva teorica kelseniana su tre punti fondamentali. Primo, la norma cessa di essere il prius logico del fenomeno giuridico. Nella prospettiva leoniana il prius è dato dall'azione giuridica, intesa come esercizio di pretese e adeguamento a pretese altrui da parte dei singoli individui. Secondo, la distinzione tra validità ed efficacia perde rilevanza teorica. Nella prospettiva leoniana l'aderenza della norma ai comportamenti individuali diviene un tratto costitutivo, per così dire "genetico", del diritto: le norme esistono se e in quanto esercitino la loro efficacia sulle menti dei singoli individui e sui loro comportamenti. Terzo, l'origine del diritto è situata nelle azioni, volizioni e convincimenti dei singoli individui, e non più nell'essere una norma emanata da autorità super-individuali legittimate da norme superiori. Sulla base di questi tre capisaldi teorici, Leoni elabora la teoria del "diritto come pretesa individuale", che si propone di superare gli ostacoli incontrati dagli approcci "puristi" o "logico-formali" al diritto. Leoni apre la strada verso una teoria scientifica del diritto imperniata su un empirismo realista di stampo sociologizzante e, insieme, sul recupero della tradizione giusfilosofica del diritto naturale.

\section{3.}

Gli scritti nei quali Leoni articola con maggiore precisione la teoria del diritto come scambio di pretese individuali sono i saggi intitolati Diritto e politica - che costituisce il testo di una relazione presentata al V Congresso italiano di Filosofia del Diritto (1961) Obbligo e pretesa nella dogmatica, nella teoria generale e nella filosofia del diritto apparso negli Studi in onore di Emilio Betti (1961) - e Il diritto come pretesa individuale - pubblicato sull'Archiv für Rechts- und Sozialphilosophie (1964). L'obiettivo teorico di Leoni è elaborare una teoria che definisca e spieghi nel modo più preciso e rigoroso

\footnotetext{
${ }^{31}$ A proposito della teoria del diritto e del positivismo giuridico, p. 230.
} 
possibile il fenomeno giuridico. La costruzione di tale teoria si snoda intorno a cinque passaggi teorici fondamentali: 1) la premessa metodologica circa il problema definitorio del diritto; 2) la definizione del concetto di pretesa; 3) il criterio distintivo della giuridicità delle pretese; 4) il rapporto tra coercizione e pretesa; 5) la produzione del diritto a partire dallo scambio di pretese individuali. È utile esaminare brevemente ciascuno di questi passaggi teorici.

3.1. Il punto di partenza del ragionamento leoniano è squisitamente metodologico: individuare il criterio in base al quale affrontare la questione definitoria del diritto da cui tutta l'indagine intorno alla natura del fenomeno giuridico è condizionata. Si tratta cioè di chiedersi, nelle parole di Leoni, «con che diritto [...] definiamo il diritto?». ${ }^{32}$ Poiché il diritto è radicato nelle azioni e volizioni dei singoli individui, il problema definitorio coincide, per Leoni, con quello di individuare quale sia il significato che alla parola "diritto" sia attribuito da coloro che agiscono sul piano giuridico. L'essenza del diritto va cercata, cioè, nel minimo significato comune attribuito alla parola "diritto" nei vari discorsi in cui tale termine è impiegato e sulla base dei quali gli individui compiono certe azioni.

L'importanza di questo punto metodologico preliminare non può essere sottovalutata. Impostando l'indagine in questi termini, Leoni si discosta radicalmente dall'approccio formale del purismo giuridico. Mentre le teorie generali "pure" trasferiscono nell'ambito della teoria generale il linguaggio dogmatico adottato dagli operatori tecnici del diritto, Leoni si spinge sino a comprendere, per quanto possibile, tutti i linguaggi in cui il termine diritto è impiegato, incluso il linguaggio degli uomini comuni. Solo in tal modo si può legittimamente ambire a una teoria "generale" del diritto. Il linguaggio della dogmatica giuridica, infatti, è condizionato dagli scopi pratici perseguiti dagli operatori del diritto (ad esempio, giustificare una decisione giudiziaria o risolvere una controversia). Pertanto, limitarsi al discorso degli operatori tecnici del diritto significa non solo limitarsi a considerare un numero ristretto di significati fra tutti quelli possibili, ma anche svolgere un'analisi fuorviante, poiché gli operatori tecnici non sono interessati a rintracciare una spiegazione dell'origine delle norme; nella loro pratica quotidiana, essi danno per scontata l'origine delle norme. ${ }^{33}$ Le teorie generali "pure", dunque, trasferiscono indebitamente sul piano teorico le concettualizzazioni elaborate per fini pratici dai giuristi dogmatici e operatori tecnici del diritto, finendo così con lo smarrire la vera essenza del diritto. Non possono escludersi dal campo d'indagine del teorico del diritto quei significati che alla parola "diritto" sono attribuiti dalla moltitudine degli uomini comuni che agiscono sul piano giuridico.

La scelta metodologica di ricercare l'essenza del diritto nell'analisi del linguaggio utilizzato da chi agisce sul piano giuridico, si rivela decisiva sul piano dei risultati dell'analisi teorica. Qualora l'indagine si spinga sino a considerare tutti i possibili linguaggi in cui è usata la parola diritto, $i$ concetti di "norma", "obbligo", o "comando" perdono il loro carattere ultimativo. Leoni afferma: «chi dice [...] "io ho

\footnotetext{
${ }^{32}$ Obbligo e pretesa, p. 340 (corsivo dell'autore).

${ }^{33}$ Obbligo e pretesa, p. 340; Il diritto come pretesa individuale, pp. 121-123.
} 
diritto di far la tal cosa" non si riferisce sempre e necessariamente, né a una norma che contenga un "obbligo", né al comando di una qualche autorità espresso nella norma. Nel suo atteggiamento mentale esiste un elemento di soggettività che appare per sua natura irriducibile a una presunta norma di tipo kelseniano»».

I concetti, al centro delle teorie normativistiche, di "norma", "obbligo" e "comando" sono inadatti a cogliere il minimo significato comune della parola "diritto". Il concetto che appare più idoneo a cogliere il significato minimo comune del termine "diritto", è quello di pretesa. Leoni afferma: "Colui che rivendica un diritto pretende anzitutto il verificarsi di un comportamento altrui». ${ }^{35} \mathrm{E}$ dunque la pretesa individuale il dato ultimo del processo giuridico, ed è da tale concetto che occorre partire per cogliere quell'essenza del diritto che le teorie normativistiche hanno finito per smarrire. Occorre ora esaminare più da vicino il concetto di pretesa individuale proposto da Leoni.

Prima di procedere è utile rilevare che la scelta metodologica di ricercare l'essenza del fenomeno giuridico nell'identificazione del minimo significato comune della parola "diritto" corrisponde a una precisa intuizione leoniana nel campo della filosofia del linguaggio. Nell'assegnare all'analisi del linguaggio il difficile compito di trovare il significato comune sotteso alla varietà degli usi della parola "diritto", Leoni si contrappone all'orientamento convenzionalista neopositivistico dominante al tempo in cui egli scriveva. Leoni osserva che di fronte alla molteplicità degli usi della parola "diritto", molti studiosi finiscono per adottare una definizione "convenzionale" di diritto. Ma, la soluzione convenzionalista è la soluzione «di chi sospende, a un certo punto, per stanchezza, o per altri motivi di comodo, la ricerca linguistica». ${ }^{36}$ "La stanchezza genera così le teorie generali insoddisfacenti». ${ }^{37}$ Come ha acutamente osservato Uberto Scarpelli, in anticipo sugli sviluppi futuri della filosofia del linguaggio, Leoni intuisce che «l'alternativa [agli] eccessi convenzionalistici [...] sarebbero venuti nella maniera più attendibile da un accostamento funzionalistico». ${ }^{38}$ Leoni intuisce, cioè, che il postulato metodologico dell'esistenza di un significato minimo comune della parola "diritto" può essere saldamente basato sul fatto che il fenomeno giuridico corrisponde in ogni società ad alcune esigenze costanti e che pertanto la parola "diritto" presenta costantemente quei significati che corrispondono a quelle esigenze. L'essenza del diritto va dunque ritrovata in quelle funzioni del diritto che corrispondono ai dati costanti di ogni esperienza giuridica. La feconda intuizione leoniana è dunque aver compreso che, nelle parole di Scarpelli, «una base di minimo significato comune [...] è costituita dall'esigenza, presente in ogni società, di esprimere pretese e coordinarle in un ordinamento giuridico». ${ }^{39}$ Il vantaggio analitico di questa prospettiva sta nel fatto che mentre le definizioni puramente convenzionalistiche del diritto finiscono per sottrarsi ai criteri di verificabilità e falsificabilità, le definizione funzionalistiche consentono di «indagare in

\footnotetext{
${ }^{34}$ Obbligo e pretesa, p. 356 (corsivo dell'autore). Si veda anche Diritto e politica, pp. 322-323.

${ }^{35}$ Obbligo e pretesa, p. 356.

${ }^{36}$ Obbligo e pretesa, p. 342.

${ }^{37}$ Obbligo e pretesa, p. 342.

${ }^{38}$ Uberto Scarpelli, "Bruno Leoni e 1'analisi del linguaggio”, Il Politico, XLVII, n. 1, 1982, p. 143.

${ }^{39}$ Uberto Scarpelli, "Bruno Leoni e l'analisi del linguaggio", p. 143.
} 
maniera insieme proficua e controllata, in rapporto a fatti osservabili, i processi di formazione e trasformazione dei significati e delle forme logiche». ${ }^{40}$

Tale impostazione metodologica è coerente con le posizioni in tema di filosofia del linguaggio che Leoni esprime nello scritto intitolato L'odierno indirizzo nominalistico nella teoria della politica e del diritto, pubblicato nel 1958, e in cui Leoni esamina gli sviluppi più recenti della tradizione filosofica logico-analitica, con particolare attenzione al passaggio dal positivismo logico alla «nuova annalistica». Con tale ultima espressione Leoni si riferisce cioè alla "filosofia analitica" affermatasi nel mondo anglosassone nel decennio successivo alla fine della seconda guerra mondiale. In questo saggio, Leoni prende le distanze dal nominalismo formalistico, sia esso articolato nella forma, più radicale e schiettamente antimetafisica, del positivismo logico del circolo di Vienna, sia esso articolato secondo lo stile, più cauto ma non meno inadeguato a spiegare il fenomeno giuridico, della più recente filosofia analitica. Dalla critica che il filosofo torinese muove al nominalismo formalistico emergono, sia pure nella veste di una critica al nominalismo formalista, alcuni temi ricorrenti nell'intera opera leoniana. Leoni critica il tentativo di ridurre la totalità della ricerca filosofica a una indagine relativa al linguaggio. Il filosofo torinese riconosce l'importanza dell'analisi del linguaggio a fini della comprensione dei fenomeni sociali, ma mette in evidenza, facendo proprie le parole con cui Bertrand Russell criticava il positivismo logico, che «[1]'assorbirsi nel linguaggio talvolta conduc[a] a trascurare la connessione del linguaggio coi fatti non linguistici, sebbene sia proprio questa connessione a dare significato alle parole e significato alle proposizioni»». Emerge qui l'atteggiamento "antipurista" esaminato in precedenza, che si declina come propensione a un'analisi del linguaggio impostata su basi empiristiche, che indaghi cioè il rapporto intercorrente fra tutti i linguaggi (filosofici, tecnici, comuni) e fra tali linguaggi e i fatti che essi descrivono. In questo senso, il saggio L'odierno indirizzo nominalistico nella teoria della politica e del diritto si rivela di notevole importanza, giacché consente al lettore e allo studioso dell'opera leoniana, di collocare in una corretta prospettiva analitica tanto l'obiezione che Leoni muove alla pretesa kelseniana di trasferire il linguaggio dogmatico dei giuristi nel campo della teoria generale, quanto le premesse metodologiche della teoria della pretesa.

3.2. In Diritto e politica Leoni individua e definisce come segue la nozione di "pretesa":

Il concetto cui sembra riducibile il termine diritto, così come viene usato nel linguaggio ordinario, è quello che potrebbe definirsi la richiesta di un comportamento altrui corrispondente a un nostro interesse (o all'interesse di altri in nome e per conto dei quali formuliamo la richiesta stessa) e considerato inoltre come probabile - e comunque più probabile di altri - nell'ambito di convivenza organizzata cui apparteniamo entrambi (noi e la persona il cui comportamento è oggetto di pretesa), nonché, in ogni caso, come determinabile mediante un nostro intervento (presso tale persona o presso altre) in base a un potere di cui noi, che formuliamo la richiesta, ci consideriamo dotati. ${ }^{42}$

\footnotetext{
${ }^{40}$ Uberto Scarpelli, "Bruno Leoni e l'analisi del linguaggio", p. 143.

${ }^{41}$ L'odierno indirizzo nominalistico nella teoria della politica e del diritto, p. 219.

${ }^{42}$ Diritto e politica, p. 331.
} 
Tale definizione chiarisce che la pretesa sottostante alla rivendicazione di un diritto è anzitutto un fatto psicologico. Essa contiene i seguenti atteggiamenti mentali da parte di chi pretende: 1) una previsione riguardante il comportamento più probabile delle altre persone; ${ }^{43}$ 2) l'intenzione di determinare il comportamento altrui, oggetto di pretesa ${ }^{44} 3$ ) un giudizio positivo sul potere di soddisfare la pretesa, cioè sulla possibilità di determinare (direttamente o indirettamente, da solo o col concorso di altri) un dato comportamento da parte di qualcuno; ${ }^{45} 4$ ) una valutazione positiva in termini d'interesse proprio del comportamento domandato o preteso. ${ }^{46}$

Leoni illustra la nozione di pretesa facendo l'esempio della pretesa del creditore di essere pagato dal proprio debitore. Alla base del diritto del creditore d'essere pagato non v'è una norma giuridica di tipo kelseniano che stabilisce l'obbligo del debitore di pagare il creditore, quanto piuttosto la pretesa del creditore di ottenere il pagamento del proprio credito. Nella pretesa creditizia sono impliciti i seguenti atteggiamenti psicologici del creditore: 1) la previsione che il suo debitore pagherà; 2) l'intenzione di essere pagato; 3) un giudizio positivo sul proprio potere di determinare il comportamento del debitore e ottenere il pagamento del debito; 4) l'interesse a essere pagato.

Il punto di distacco rispetto al normativismo kelseniano sta nel fatto che la pretesa del creditore precede logicamente l'obbligo del debitore.

Occorre tuttavia rilevare che la priorità logica della pretesa rispetto all'obbligo espresso dalla norma può essere compresa solo ove si tenga in dovuto conto l'elemento oggettivo della pretesa. L'atteggiamento psicologico del "pretendere" non è in grado di fondare da solo la giuridicità della pretesa e dimostrarne la priorità logica rispetto ai concetti di norma e obbligo. L'atteggiamento psicologico del pretendere acquista rilevanza giuridica solo qualora esso abbia ad oggetto un comportamento statisticamente probabile. Il pretendere soggettivo si fonda, dunque, su calcoli e anticipazioni concernenti la probabilità che la pretesa, qualora avanzata, sia soddisfatta in un dato ambito storico. Per cui la giuridicità dipende, in definitiva, sia da una componente soggettiva - previsione, intenzione, potere e interesse - che da una componente oggettiva concernente la probabilità del comportamento dei singoli individui in un dato ambito storico. È utile chiarire in cosa consista, secondo Leoni, la componente oggettiva della pretesa giuridica.

3.3. Il progetto leoniano di fondare la teoria del diritto sul concetto di pretesa deve tenere conto del fatto che non tutte le pretese sono considerate giuridiche nel linguaggio ordinario. Si pone pertanto il problema di distinguere le pretese "giuridiche" da quelle "antigiuridiche" o da quelle, più semplicemente, "agiuridiche". Qui Leoni introduce un elemento di notevole originalità che segna un ulteriore radicale scostamento dal positivismo giuridico: l'essenza del diritto è radicata non nella norma ma nel dato, tutto empirico, della probabilità statistica concernente la soddisfacibilità di determinate pretese individuali.

\footnotetext{
${ }^{43}$ Diritto e politica, p. 323; Obbligo e pretesa, p. 357; Il diritto come pretesa individuale, p. 130.

${ }^{44}$ Diritto e politica, p. 325.

${ }^{45}$ Diritto e politica, p. 325-326; Obbligo e pretesa, p. 358.

${ }^{46}$ Diritto e politica, p. 327; Il diritto come pretesa individuale, p. 130.
} 
Il normativista kelseniano, posto di fronte al dilemma di distinguere pretese giuridiche e antigiuridiche, è indotto ad affermare che ciò che consente di individuare, tra tutte le pretese presenti in una società, la pretesa "giuridica" è l'esistenza di una norma giuridica. Da questa prospettiva, le pretese giuridiche sono quelle che osservano le norme giuridiche, mentre quelle antigiuridiche sono quelle che violano il comando in esse contenuto. Ad esempio: la norma che esprime il comando "non rapinare" consente di stabilire l'antigiuridicità dell'eventuale pretesa del rapinatore di rapinare la vittima; analogamente, la norma che esprime il comando "paga i tuoi debiti" consente di stabilire l'antigiuridicità dell'eventuale pretesa di un debitore di non pagare i propri debiti.

In contrasto con tale approccio, Leoni afferma che per stabilire la giuridicità o antigiuridicità di una pretesa è bensì necessaria una regula, ma tale regola non ci è fornita da una norma giuridica di tipo kelseniano, quanto piuttosto da una regola di tipo statistico, cioè, una descrizione di eventi concreti in base a uno schema probabilistico dei comportamenti tenuti in una data società ${ }^{47}$ Leoni afferma: «La nozione classica di id quod plerumque accidit appare pienamente idonea a suggerire quale sia la vera natura della "norma", o della "regola" cui si fa riferimento per distinguere le pretese comunemente ritenute "antigiuridiche" da quelle comunemente ritenute "giuridiche». ${ }^{48}$

Ad esempio: «[1]a probabilità statistica che un passante si trasformi in un rapinatore non appena incontri un altro passante in una via solitaria è relativamente modesta e comunque inferiore alla probabilità contraria, in tutte le società destinate a durare come tali per un ragionevole lasso di tempo». ${ }^{49}$ Ciò consente di stabilire che la pretesa del rapinatore di impossessarsi con violenza del denaro del passante è antigiuridica, mentre è giuridica la pretesa del passante di non essere rapinato. «Analoga considerazione vale per la probabilità statistica che chi contrae un debito non intenda pagarlo» ${ }^{50} \mathrm{La}$ probabilità statistica che un debitore avanzi la pretesa di non pagare il debito contratto e che tale pretesa sia soddisfatta è relativamente modesta. Pertanto la pretesa del debitore di contrarre un debito e non pagarlo è antigiuridica, mentre è giuridica la pretesa del creditore di ottenere il pagamento di quanto dovuto. ${ }^{51}$

Leoni radica dunque la "normatività" nella "normalità". La probabilità statistica che una determinata pretesa sia avanzata e soddisfatta in un determinato ambito storico e sociale fonda la giuridicità della pretesa. Come ha efficacemente chiarito Gavazzi: «la norma nel senso specifico che le dà Leoni si iscrive tutta intiera nella normalità (nel id quod plerumque accidit)...». ${ }^{52}$

Questo punto è ulteriormente specificato ne Il diritto come pretesa individuale in cui Leoni aggiunge che il criterio della probabilità statistica consente di classificare le pretese in "giuridiche", "agiuridiche" e "antigiuridiche". Leoni illustra tale classificazione come segue:

\footnotetext{
${ }^{47}$ Il diritto come pretesa individuale, p. 128.

${ }^{48}$ Diritto e politica, p. 324.

${ }^{49}$ Diritto e politica, p. 324. Si veda anche Obbligo e pretesa, p. 357.

${ }^{50}$ Diritto e politica, p. 324. Si veda anche Obbligo e pretesa, p. 357.

${ }^{51}$ Diritto e politica, p. 324; Obbligo e pretesa, p. 357.

${ }^{52}$ Giacomo Gavazzi, "Conclusioni”, in AA.VV., "Il pensiero politico e giuridico di Bruno Leoni”, Il Politico, XLVII, n. 1, 1982, p. 180.
} 
Suggerisco di chiamare "giuridiche" precisamente quelle domande o pretese che hanno un'elevata probabilità di essere soddisfatte dalle persone corrispondenti in una data società e in un dato periodo, essendo variabili le ragioni per cui esse possono essere soddisfatte in ogni singolo caso [...] Al contrario, "domande o pretese antigiuridiche" sono quelle con scarse o nessuna probabilità di essere soddisfatte dalle persone corrispondenti in circostanze normali (come quella di un rapinatore che agisca in pieno giorno in una strada affollata). ${ }^{53}$

Infine:

[n]on si deve dimenticare [...] l'enorme settore intermedio di meno facilmente definibili pretese "quasi giuridiche" o "quasi-antigiuridiche", le cui probabilità di essere soddisfatte sono più basse di quelle delle pretese chiaramente "giuridiche", ma ancora più alte di quelle palesemente "antigiuridiche". ${ }^{4}$

Prima di procedere nell'illustrare le implicazioni giusfilosofiche della teoria della pretesa, è opportuno sottolineare che il tema della probabilità - che ne costituisce dunque il perno centrale - è al centro della riflessione leoniana sin dagli anni giovanili. Da questo punto di vista, il saggio intitolato Probabilità e diritto nel pensiero di Leibniz, pubblicato nel 1947, si rivela di fondamentale importanza per comprendere la radice intellettuale e il fondamento filosofico della teoria della pretesa. ${ }^{55}$ In esso Leoni approfondisce il rapporto che sussiste, nella storia delle idee, tra «concetti e problemi propri del calcolo delle probabilità» e i «problemi e concetti del mondo umano, in particolare del dominio storico, giuridico e politico». ${ }^{56}$ Leoni mette in evidenza «che la stessa origine del calcolo si debba in gran parte all'esigenza di risolvere una questione di diritto». ${ }^{57} \mathrm{Si}$ tratta della questione sottoposta dal cavalier de Méré a Pascal, concernente la ripartizione di poste di gioco tra due giocatori d'azzardo, ciascuno dei quali versa come posta la medesima somma di denaro, con l'intesa che otterrà la vittoria chi vincerà per primo tre partite. Dopo che uno dei due giocatori vince due partite, al momento di giocare la terza partita, $\mathrm{i}$ giocatori debbono separarsi e dividersi la posta versata. Come procedere alla divisione? Leoni evidenzia come le soluzioni date al problema da Pascal e da Pierre de Fermat «partano entrambe dalla tacita premessa che la ripartizione delle poste debba farsi secondo l'esatta proporzione delle probabilità che ognuno dei giocatori avrebbe di vincere tre partite (e quindi il totale delle poste) se il gioco potesse continuare». ${ }^{58} \mathrm{Si}$ chiarisce così che uno dei problemi dai quali trae origine il calcolo delle probabilità «non soltanto è nella sua essenza un problema giuridico», ma «suggerisce una risposta anch'essa fondata su un presupposto schiettamente giuridico». ${ }^{59}$ In altre parole, il

\footnotetext{
${ }^{53}$ Il diritto come pretesa individuale, p. 129.

${ }^{54}$ Il diritto come pretesa individuale, p. 129.

${ }^{55}$ Un altro scritto degli anni giovanili dedicato al tema della probabilità è Norma, previsione e speranza nel mondo storico, nel volume I di quest'opera.

${ }^{56}$ Probabilità e diritto nel pensiero di Leibniz, pp. 255-256.

${ }^{57}$ Probabilità e diritto nel pensiero di Leibniz, p. 256.

${ }^{58}$ Probabilità e diritto nel pensiero di Leibniz, pp. 256-257 (enfasi aggiunta).

${ }^{59}$ Probabilità e diritto nel pensiero di Leibniz, p. 257.
} 
problema giuridico della ripartizione delle poste di gioco non può risolversi solo sulla base del calcolo delle probabilità, ma per la sua risoluzione occorre poter affermare il principio giuridico secondo cui «i diritti maturati dai contraenti durante l'esecuzione del contratto aleatorio [...] [sono] rigorosamente proporzionali alle alee di ognuno dei contraenti al momento della risoluzione del contratto stesso». ${ }^{60}$ Questa parte del ragionamento leoniano contiene già in nuce l'elemento fondamentale della teoria della pretesa elaborata e chiarita da Leoni negli anni successivi. Tale elemento consiste nell'idea che l'aspettativa giuridicamente rilevante sia quella radicata nel calcolo della probabilità che tale pretesa possa venire avanzata e soddisfatta. ${ }^{61}$

Non v'è chi non veda come il radicamento della giuridicità nella probabilità statistica delle pretese individuali ribalti completamente gli assunti teorici del normativismo purista, e in particolare di quello kelseniano. Mentre per i normativisti la pretesa individuale è la conseguenza logica della norma; per Leoni il concetto di pretesa precede logicamente quello di norma e ne determina il contenuto. Non è la norma che fonda la giuridicità di una pretesa, ma la giuridicità della pretesa che determina il contenuto della norma. In definitiva, il prius logico del processo giuridico non è più la norma contenente un obbligo giuridico, ma la pretesa individuale statisticamente probabile.

Gavazzi ha efficacemente illustrato il radicale cambiamento di prospettiva impresso da Leoni al normativismo kelseniano con le seguenti parole: «La normatività nel vecchio senso è stata espunta dalla teoria di Leoni [...] prima pareva una normatività passiva, dal punto di vista di chi - gli individui - se la vedeva piombare addosso come un fulmine e che venisse dagli dei, dal sovrano o dal popolo poco importava: io devo! In Leoni diventa una normatività attiva, forse aggressiva: io, io voglio, io pretendo. Ma ha cambiato anche sede: dall'esterno degli individui, da una sorta di panopticon, Leoni l'ha portato all'interno degli individui e di ciascun individuo». ${ }^{62}$ Queste parole di Gavazzi hanno il merito di evidenziare il passaggio da una concezione purista del normativismo, quale quella kelseniana, a una concezione che collega il normativismo a un rigoroso individualismo metodologico e teorico.

Infine, occorre rilevare come Leoni sottolinei a più riprese i vantaggi tecnici della teoria della pretesa rispetto all'impostazione normativista: la precedenza logica del concetto di pretesa consente di risolvere il problema della distinzione della norma giuridica da altri tipi di norma - problema che l'impostazione kelseniana lascia insoluto. ${ }^{63}$ I fautori della teoria normativista tendono a risolvere il problema della distinzione della norma giuridica da altri tipi di norma individuando nella coercibilità il tratto distintivo della norma giuridica. Così facendo, tuttavia, essi escludono dalla definizione di diritto «una serie imponente di usi linguistici in base ai quali sono "giuridiche" norme non coercibili». ${ }^{64}$ Nella realtà degli ordinamenti giuridici molte norme solitamente considerate come

\footnotetext{
${ }^{60}$ Probabilità e diritto nel pensiero di Leibniz, p. 257.

${ }^{61}$ Cfr. Silvia Menocci, L'antiformalismo di Bruno Leoni nei suoi rapporti con le correnti del realismo giuridico, DiGips, Siena, 2003 pp. 15-18; Carlo Lottieri, Le ragioni del diritto. Libertà individuale e ordine giuridico nel pensiero di Bruno Leoni, pp. 105-109.

${ }^{62}$ Giacomo Gavazzi, "Conclusioni”, in AA.VV., "Il pensiero politico e giuridico di Bruno Leoni”, p. 181.

${ }^{63}$ Diritto e politica, p. 328; Obbligo e pretesa, p. 354.

${ }^{64}$ Diritto e politica, p. 354.
} 
"giuridiche" sono prive di ogni aspetto coercitivo, né esse contengono un richiamo alla coattività nella loro formulazione. ${ }^{65} \mathrm{Si}$ pensi, ad esempio, a «molte norme del diritto privato, talune norme del diritto costituzionale, la maggior parte di quelle del diritto internazionale o di quello canonico, o infine di quello consuetudinario, là dove si ammette il diritto consuetudinario come diritto autonomo». ${ }^{66}$ Anche il concetto di "norma obbligatoria" non giova a indentificare ciò che caratterizza, e ciò da cui dipende, la giuridicità della norma. Scrive Leoni: «Il concetto di obbligo appare [...] insufficiente a corrispondere a una vasta area di significati della parola "diritto" che pur si usano nel linguaggio comune». ${ }^{67}$ Neppure il concetto di Sollen, inteso come infinito del verbo "dovere", e con cui Kelsen identifica l'essenza della norma obbligatoria, è risolutivo a tal proposito. Il termine Sollen è «troppo generico per consentire una vera comprensione della natura dei due tipi di obbligo, quello "giuridico" e quello morale». ${ }^{6}$

A fronte di tali ostacoli concettuali, il concetto di "pretesa" sembra offrire quei vantaggi teorici che i concetti di norma "obbligatoria" e di "obbligo" non riescono a offrire. ${ }^{69} \mathrm{Se}$ il termine Sollen non consente di distinguere tra obblighi morali e giuridici, l'espressione "tu devi" rende invece chiaro che a ogni "tuo" dovere corrisponde un "io pretendo da te". L'espressione "tu devi" richiama alla nostra mente un dato che il termine Sollen (inteso come infinito del verbo dovere) lascia inspiegato, e cioè che l'essenza della giuridicità può essere colta nell'intersubiettività delle pretese individuali, non nel generico e indeterminato concetto di "dovere".

In estrema sintesi, il "dovere" diviene "giuridico" solo quando a esso corrisponda una pretesa individuale. Come scrive efficacemente Leoni:

L'obbligo giuridico come tale non esiste: esso viene a definirsi come giuridico soltanto se ridotto logicamente alla pretesa che gli corrisponde, non vi è ad esempio possibilità di concepire un obbligo del debitore, se non esiste una qualche pretesa, attuale o almeno possibile, da parte del creditore. ${ }^{70}$

3.4. Dopo aver definito il concetto di pretesa, identificato il criterio distintivo delle pretese giuridicamente rilevanti, e chiarita la precedenza logica della pretesa rispetto alla norma, Leoni si cura di esaminare il processo di formazione del diritto, che, a suo giudizio, la teoria normativista kelseniana non è in grado di spiegare. La tesi centrale di Leoni è che vi sia una fondamentale analogia tra il processo di formazione del diritto e il processo di funzionamento del mercato. ${ }^{71}$ In Obbligo e Pretesa, egli scrive:

Il diritto e, rispettivamente il mercato, nascono da incontri, l'uno di pretese relative a determinati comportamenti, l'altro di scelte relative a determinati beni, e come tali rappresentano entrambi processi

\footnotetext{
${ }^{65}$ Il diritto come pretesa individuale, p. 124.

${ }^{66}$ Obbligo e pretesa, p. 354.

${ }^{67}$ Obbligo e pretesa, p. 356.

${ }^{68}$ Diritto e politica, p. 328.

${ }^{69}$ Obbligo e pretesa, p. 356.

${ }^{70}$ Obbligo e pretesa, p. 360 (corsivo dell'autore).

${ }^{71}$ Diritto e politica, pp. 326-327 e 331; Obbligo e pretesa, pp. 358-366.
} 
senza fine nel corso dei quali si commettono bensì errori, ma in conseguenza dei quali si instaurano spesso faticosamente - regolarità, che sono oggetto di previsioni e di pretese determinanti a loro volta altre previsioni e altre pretese. ${ }^{72}$

Questo passaggio sintetizza il nucleo fondamentale della concezione leoniana del diritto quale fenomeno sociale che scaturisce da una molteplicità di scambi interindividuali. L'analogia strutturale tra diritto e mercato si articola in due parallelismi. Primo, le pretese individuali svolgono sul piano giuridico una funzione analoga a quella che le domande e offerte di beni e servizi svolgono in un'economia di mercato. Secondo, il processo di formazione delle norme giuridiche è analogo al processo di formazione dei prezzi di mercato: come l'incontro e la confluenza di domande e offerte di beni servizi generano prezzi di mercato, così l'incontro e la confluenza di pretese individuali generano norme giuridiche.

L'analogia strutturale tra diritto e mercato conferma che «il concetto di obbligo giuridico espresso nella norma giuridica viene a dipendere logicamente dal concetto di pretesa». ${ }^{73}$ Così come la domanda e l'offerta di beni e servizi precedono logicamente la formazione del prezzo, così le pretese avanzate dai singoli precedono logicamente la norma e l'obbligo giuridico. Le norme registrano l'equilibrio raggiunto tra le pretese avanzate e soddisfatte in una determinata società, così come il prezzo registra l'equilibrio raggiunto tra quantità di beni e servizi domandate e offerte sul mercato. Inoltre, l'analogia strutturale tra diritto e mercato illustra come il diritto sia in larga misura il risultato inintenzionale degli sforzi dei singoli volti a vedere soddisfatte le proprie pretese o adattarsi alle pretese altrui. Scrive Leoni: «Considerato nel suo aspetto dinamico, il diritto è dunque una continua serie di tentativi, che gli individui compiono quando pretendono un comportamento altrui, e si affidano al proprio potere di determinare quel comportamento, qualora esso non si determini in modo spontaneo». ${ }^{74}$ Il diritto si forma «senza [...] che gli operatori giuridici abbiano bisogno di ricostruire l'intero processo di formazione del sistema delle norme attraverso l'analisi dell'incontro e dello scambio delle pretese, e attraverso l'analisi di quell'operazione del pretendere che in definitiva condiziona tutto il processo giuridico». ${ }^{75}$ In definitiva, il diritto è il risultato inintenzionale dello scambio di pretese individuali piuttosto che il risultato di un disegno finalistico corrispondente alla volontà di un legislatore.

3.5. Chiariti gli aspetti tecnico-filosofici che distinguono la teoria della pretesa dal normativismo kelseniano, occorre ora sottolineare come la teoria giusfilosofica della pretesa rechi con sé una fondamentale implicazione filosofico-politica. Nell'affermare la precedenza logica della pretesa rispetto alla norma, Leoni spezza il legame concettuale tra diritto e coercizione così com'esso è tradizionalmente postulato dalle dottrine

72 Obbligo e pretesa, p. 363 (enfasi aggiunta).

73 Obbligo e pretesa, p. 359.

${ }^{74}$ Obbligo e pretesa, p. 358

${ }^{75}$ Obbligo e pretesa, pp. 358-359. 
positivistiche. ${ }^{76}$ Poiché nessuna pretesa è possibile senza la volontà e senza l'interesse di chi avanza la pretesa, ${ }^{77}$ affermare che il concetto di norma (e di obbligo) dipendono interamente dal concetto di pretesa significa affermare che il prodursi del diritto dipende dalle volizioni, previsioni, e interessi dei singoli individui che avanzano pretese. Lo scostamento teorico dal normativismo purista non potrebbe essere più radicale. Per i normativisti kelseniani il diritto nasce dall'intervento coercitivo di un'autorità che emana comandi "depsicologizzati" (indipendenti, cioè, dai reali processi psicologici di volontà dei suoi destinatari); per Leoni, il diritto scaturisce dai convincimenti, azioni e interessi dei singoli individui.

Si pensi all'esempio del diritto del creditore che vuole essere pagato dal suo debitore. Nell'impostazione leoniana, come s'è visto, ciò che fonda la giuridicità della pretesa creditizia sono i requisiti empirici della volontà del creditore di essere pagato, la previsione che il debitore in circostanze normali pagherà, il giudizio positivo circa il potere di disporre dei mezzi per determinare il comportamento del debitore, e infine, la probabilità statistica che la pretesa del creditore in circostanze normali sia avanzata e soddisfatta. Dunque, la coercizione non è necessaria affinché la pretesa del creditore sia qualificabile come giuridica. Scrive Leoni:

[P]uò darsi che il debitore paghi di sua volontà, che lo faccia non appena il creditore gli ricorda il suo debito, dopo una discussione o dopo un rimprovero, e così via. Anche quando il creditore fa ricorso alla cosiddetta coercizione (o alla sua minaccia), questo concetto non è cosi rilevante all'interno dell'intero processo, come potrebbe sembrare a prima vista, poiché la coercizione imposta al debitore richiede la cooperazione delle persone che devono applicarla». ${ }^{78}$

In ogni caso, dunque, la pretesa del creditore è giuridica non perché è coercibile in conformità a qualche norma di tipo kelseniano, ma perché essa si fonda sulla volontà del creditore di ottenere da altre persone un comportamento previsto come statisticamente probabile in quel dato contesto sociale. La coercizione non crea la giuridicità, ma si limita ad assisterla in un numero limitato di casi.

In tal modo, Leoni sgretola la base concettuale su cui si fonda l'identificazione positivistica di diritto e volontà politica. La precedenza logica della pretesa rispetto alla norma conduce all'inevitabile superamento dell'idea secondo cui l'unico vero diritto sia quello posto, o "imposto", dai detentori del potere politico. La teoria della pretesa afferma il principio che il diritto è per sua natura indipendente dalla volontà dei governanti. In quest'ottica, la creazione di norme giuridiche tramite la tecnica della legislazione cessa di essere l'origine dell'intero processo giuridico. ${ }^{79}$ Da questo punto di vista, come osservato da numerosi commentatori, la teoria della pretesa è riconducibile

\footnotetext{
${ }^{76}$ Negli anni in cui Leoni scriveva i suoi contributi sulla teoria della pretesa, il filosofo del diritto italiano che più si avvicinò a certi aspetti della critica leoniana al positivismo giuridico fu Nicola Matteucci, nel suo celebre saggio sui rapporti tra positivismo giuridico e costituzionalismo; Nicola Matteucci, "Positivismo giuridico e costituzionalismo", Rivista trimestrale di diritto e procedura civile, n. 3, 1963, pp. 985-1100.

${ }_{78}$ Il diritto come pretesa individuale, p. 130.

${ }_{78}^{7 l}$ diritto come pretesa individuale, p. 130.

${ }^{79}$ Il diritto come pretesa individuale, p. 133.
} 
alla tradizione di pensiero libertaria ${ }^{80} \mathrm{Ma}$ per comprendere appieno le implicazioni politico-istituzionali della teoria della pretesa, occorre esaminare ora più da vicino la concezione leoniana delle fonti di produzione del diritto.

\section{4.}

La teoria del diritto come pretesa costituisce la premessa logica della concezione leoniana delle fonti di diritto. Mentre la teoria del diritto come pretesa si propone di fornire una spiegazione causale del fenomeno giuridico, l'analisi leoniana delle fonti del diritto si colloca esplicitamente sul piano normativo. Essa si propone cioè di tracciare un modello giuridico ideale che funga da parametro citrico rispetto alla valutazione della realtà istituzionale dei processi di produzione giuridica. La teoria normativa delle fonti è discussa nel celebre saggio La libertà e il diritto. ${ }^{81}$ Tuttavia, gli scritti che qui si commentano contengono già una chiara illustrazione del nesso logico che collega la teoria della pretesa a quella teoria delle fonti di produzione giuridica. È utile esaminare distintamente due snodi fondamentali del ragionamento leoniano: 1) il modello ideale delle fonti di produzione del diritto; 2) la critica ai processi concreti istituzionali di produzione giuridica nelle società contemporanee.

4.1. Leoni ritiene che il compito dei processi istituzionali di produzione giuridica sia quello di registrare o descrivere le pretese statisticamente giuridiche. Poiché, come si è visto, il diritto nasce per sua natura dall'interazione e connessione reciproca di pretese individuali, il compito dei processi istituzionali di produzione giuridica è quello di registrare imparzialmente le pretese avanzate e soddisfatte con maggiore probabilità in un determinato ambito sociale.

Inoltre, le fonti del diritto possono assolvere la funzione di facilitare lo scambio delle pretese individuali. Poiché l'incontro e lo scambio di pretese dipende, in definitiva, dai convincimenti degli individui circa la giuridicità delle proprie e altrui pretese, tale incontro o connessione sarà tanto più facile quanto più $i$ convincimenti individuali coincidano o siano, per lo meno, complementari. Le fonti del diritto possono facilitare la propagazione nella società di convincimenti sufficientemente omogenei su ciò che costituiscano pretese "giuridiche". Ogni pretesa individuale contiene «almeno in nuce, l'idea di un intero ordinamento giuridico (inteso come incontro e come scambio e comunque come connessione di pretese) che può coincidere, o meno, con le idee

\footnotetext{
${ }^{80}$ Cfr. Mario Stoppino, L'individualismo integrale di Bruno Leoni, in Bruno Leoni, Scritti di scienza politica e di teoria del diritto, Milano, Giuffrè, 1980; Mario Stoppino, "La grande dicotomia diritto privato - diritto pubblico e il pensiero di Bruno Leoni", pp. 126-130; Mario Stoppino, "Introduzione" a Bruno Leoni, Le pretese e i poteri: le radici individuali del diritto e della politica, pp. xxi-xxiii; Raimondo Cubeddu, "Sul concetto di stato nella Scuola Austriaca", Diritto e Cultura, n. 1, 1998; Fabio Massimo Nicosia, "L'anarchismo giuridico di Bruno Leoni”, Materiali per una storia della cultura giuridica, pp. 153-170; Mauro Barberis, "La teoria del diritto di Bruno Leoni”, p. 282; Antonio Masala, Il liberalismo di Bruno Leoni; Carlo Lottieri, Le ragioni del diritto. Libertà individuale e ordine giuridico nel pensiero di Bruno Leoni, Soveria Mannelli, Rubbettino, 2006, pp. 262-272.

${ }^{81}$ Volume II di quest'opera.
} 
analoghe contenute in nuce nelle pretese altrui». ${ }^{82}$ Le fonti istituzionali del diritto (come, ad esempio, il lavoro dei giudici, giureconsulti e legislatori) sono «tecniche poste in atto in ogni convivenza organizzata [...] per la propagazione d'idee uniformi su ciò che debba intendersi per "ordinamento" delle pretese e degli obblighi corrispondenti». ${ }^{83} \mathrm{La}$ propagazione d'idee uniformi sulla giuridicità delle pretese non deve essere intesa nel senso d'imposizione coercitiva di norme. Le fonti istituzionali del diritto non impongono coercitivamente delle pretese, né cercano di sostituirsi al libero gioco d'incontro, scambio e connessione di pretese individuali. Le fonti istituzionali del diritto registrano e facilitano, ma non prescrivono, i contenuti dello scambio di pretese.

Al fine di illustrare il modello ideale di produzione giuridica, Leoni ricorre, ancora una volta, all'analogia tra diritto ed economia. I processi istituzionali di produzione giuridica devono tendere il più possibile verso un modello analogo alla forma concorrenziale di mercato. L'avvicinamento ideale della produzione giuridica al modello concorrenziale di mercato mira a realizzare il principio di libertà individuale nell'ambito del diritto. Nello scritto intitolato La fabbrica del diritto, Leoni auspica un modello di organizzazione delle fonti di produzione giuridica nel quale i "consumatori" del diritto (cioè i destinatari delle regole giuridiche) siano anche i "produttori" del diritto. ${ }^{84}$ Così come nel mercato concorrenziale «il consumatore indirizza, regola e domina la condotta dei produttori», ${ }^{85}$ così nell'ambito della produzione giuridica i destinatari del diritto devono poter dominare la produzione delle regole giuridiche.

Il diritto non è presentato ai suoi destinatari come un prodotto prefabbricato, rispetto al quale essi non hanno altro compito che quello di usarlo "già pronto"; al contrario, «il diritto è qualcosa che fanno tutti ogni giorno, col loro comportamento, colla loro spontanea accettazione e colla non meno spontanea osservanza delle regole che ciascuno di essi contribuisce a stabilire...». ${ }^{86}$ Ancora una volta, Leoni mira a separare la produzione giuridica dal potere coercitivo dei detentori del potere politico e a radicarla il più possibile nelle libere azioni, volizioni e convincimenti dei singoli individui.

4.2. Illustrato il modello ideale di una produzione concorrenziale e individualistica del diritto, a Leoni non sfugge che nella realtà gli individui operanti nell'ambito dei processi istituzionali di produzione giuridica non si limitino a formulare previsioni e predizioni circa le pretese statisticamente giuridiche, ma essi cerchino di far sì che queste predizioni abbiano successo intervenendo direttamente nel processo giuridico. È un fatto, cioè, che «la norma legislativa, la risposta del giureconsulto, la costruzione delle norme del diritto comune, la decisione del giudice, ecc., sono ad un tempo sempre descrizioni di pretese altrui ed espressioni esse stesse di pretese dei loro autori». ${ }^{87}$ In altre parole, gli operatori istituzionali del diritto sono individui che si trovano nella posizione particolare di poter

\footnotetext{
${ }^{82}$ Obbligo e pretesa, p. 363. Si veda anche, Diritto e politica, p. 331.

${ }^{83}$ Obbligo e pretesa, p. 363. Si veda anche Diritto e politica, p. 331.

${ }^{84}$ Cfr. anche Bruno Leoni, "La sovranità del consumatore e la legge", in La sovranità del consumatore, Roma, Ideazione editrice, 1977, pp. 114-121.

${ }^{85}$ La fabbrica del diritto, p. 64.

${ }^{86}$ La fabbrica del diritto, p. 66 (corsivo dell'autore).

${ }^{87}$ Obbligo e pretesa, p. 361 (corsivo dell'autore).
} 
influenzare l'intero processo giuridico sovrapponendo artificialmente le proprie particolaristiche pretese a quelle statisticamente più diffuse nella società. Nell'atto di creare, interpretare e applicare le norme giuridiche tali individui spesso registrano surrettiziamente come altrui delle pretese proprie che, in realtà, non corrispondono a comportamenti statisticamente probabili. In tal modo, essi arrecano distorsioni all'intero processo giuridico.

Anche su questo punto soccorre l'analogia tra diritto e mercato, la quale serve a illustrare non solo il funzionamento del processo giuridico, ma anche il suo malfunzionamento. ${ }^{88}$ La presenza d'individui in grado di influenzare artificiosamente il processo giuridico costituisce una distorsione di quel meccanismo dinamico cui, come s'è visto, dovrebbe essere affidato il compito di produrre regole giuridiche. Si può dire che gravino sul processo giuridico dei fallimenti istituzionali strutturalmente simili ai fallimenti di mercato. Leoni scrive: «[1]a norma legislativa, o la decisione del giudice, o il responso del prudente $[\ldots]$ possono essere considerate un listino prezzi compilato in un mercato assai imperfetto e opaco, su cui gravi più di un sospetto circa l'imparzialità dei compilatori». ${ }^{89}$ Emerge, dunque, una diffidenza di Leoni nei confronti di tutti i processi istituzionali di produzione del diritto, poiché in essi è insita la tendenza da parte degli operatori giuridici tecnici a influenzare a proprio vantaggio le probabilità delle pretese giuridiche già esistenti.

Le critiche di Leoni si appuntano in modo particolare sulla produzione del diritto mediante l'impiego della tecnica legislativa, che ai suoi occhi rappresenta lo schema organizzativo di produzione giuridica più distante dal modello ideale di una produzione del diritto radicata nelle azioni e volizioni dei singoli. Ne La fabbrica del diritto, Leoni mette a fuoco la differenza tra il rapporto in cui si trovano produttori e consumatori di beni e servizi in un mercato concorrenziale e il rapporto che invece intercorre tra produttori e consumatori di regole giuridiche prodotte mediante il processo tecnicolegislativo. Tale confronto spiega, almeno in parte, i fallimenti caratteristici della produzione del diritto in via legislativa. In un'economia di mercato i produttori di beni e servizi «si studiano bensì di allettar[e] [il consumatore] [...] sanno di doverlo sempre in definitiva servire, ossia di doverne soddisfare la volontà»; ${ }^{90}$ essi «non hanno a disposizione la polizia o l'esercito per costringere "i consumatori" a comprare i prodotti che essi [...] immettono sul mercato». ${ }^{91}$ Diversamente, la tecnica legislativa consente a un numero limitato d'imprenditori di dominare la produzione del diritto, fabbricando regole per l'uso di tutti. Il controllo dei destinatari delle regole giuridiche sulla produzione delle medesime è affidato al meccanismo della rappresentanza politica, che non consente al processo legislativo di tenere conto della volontà di tutti i destinatari delle regole giuridiche. ${ }^{92}$ I rappresentati (cioè i "consumatori”" delle regole giuridiche)

\footnotetext{
${ }^{88}$ Questo punto prefigura i moderni insegnamenti della public choice. Esso viene sviluppato in modo più compiuto in La libertà e il diritto.

${ }^{89}$ Obbligo e pretesa, p. 362.

${ }^{90}$ La fabbrica del diritto, p. 64.

${ }^{91}$ La fabbrica del diritto, p. 64.

${ }^{92}$ Leoni sviluppa in modo più articolato una critica alla rappresentanza politica in Bruno Leoni - Luigi V. Majocchi, "Una teoria 'neo-Jeffersoniana' della funzione del potere giudiziario in una società democratica", Il Politico, XXIX, n. 2, 1964, pp. 357-375.
} 
possono esprimere il loro voto «solo in certi tempi, a certe condizioni, con significato quasi sempre lacunoso ed equivoco, con effetti non sempre previsti, spesso non prevedibili, e non di rado non voluti». ${ }^{93}$ Inoltre, mentre sul mercato tutti i consumatori possono esprimere le proprie preferenze («sul mercato vota anche il ragazzino di cinque anni che abbia in mano un pezzo da cinquanta lire per comprarsi il gelato»), ${ }^{94}$ non tutti i consumatori di regole giuridiche possono votare a causa delle restrizioni di accesso al diritto di voto. Infine, una parte di consumatori, quella che si trova in minoranza nella votazione, «è destinata puramente e semplicemente a sprecare il proprio voto». ${ }^{95}$ In definitiva, solo una parte dei consumatori delle regole giuridiche prodotte mediante tecnica legislativa è nelle condizioni di poter esprimere e far valere le proprie preferenze. Di conseguenza, laddove il diritto è prodotto dai detentori del potere politico mediante il processo tecnico-legislativo il rapporto tra produttori e consumatori di regole giuridiche è strutturalmente sbilanciato a vantaggio dei produttori. Il risultato è un diritto legislativo che non tiene conto delle pretese statisticamente giuridiche in un determinato ambito sociale. In Obbligo e Pretesa, Leoni scrive:

La norma legislativa somiglia $[\ldots]$ a un listino prezzi che rifletta non soltanto transazioni reali, ma anche transazioni fittizie, miranti a prospettare non già prezzi di mercato, corrispondenti cioè all'incontro di tutte le domande e di tutte le offerte dei corrispondenti beni, ma solo ad alcune domande o ad alcune offerte, artatamente presentando quelli che sono prezzi particolari come risultanti dal processo di incontro di tutte le domande e di tutte le offerte attraverso transazioni reali, ossia come prezzi di mercato. ${ }^{96}$

Tale analisi trova conferma nell'osservazione empirica dello stato d'incertezza e inefficienza in cui versa lo Stato legislativo contemporaneo. Ne La fabbrica del diritto l'esperienza della legislazione contemporanea è descritta da Leoni come quella in cui «il diritto di oggi [...] nega quello di ieri sera ed è negato da quello di domani mattina» $\mathrm{e}$ in cui «il carattere evidentemente effimero di molta attività legislativa, dovuta al prevalere di non meno effimere maggioranze in Parlamento» determina «la conseguente impossibilità, per i cittadini, di fare piani a lunga scadenza in cui possa rientrare, come oggetto di pretesa, la costanza di regole giuridiche». ${ }^{97}$ In sostanza, l'utilizzo della legislazione per i fini particolaristici e contingenti propri del ceto politico, impedisce l'emersione di quelle regolarità statistiche che solo un processo evolutivo consuetudinario o giurisprudenziale può far emergere nel tempo.

All'incertezza e all'inefficienza si aggiunge la persistente violazione del principio di libertà. Infatti, laddove il diritto è prodotto in via legislativa, si verifica «la non meno grave conseguenza che la regola di oggi possa esser dovuta (come non di rado accade) all'intenzione oppressiva di una piccola maggioranza o persino di una effettiva minoranza

\footnotetext{
${ }^{93}$ La fabbrica del diritto, p. 64.

${ }^{94}$ La fabbrica del diritto, p. 64.

${ }^{95}$ La fabbrica del diritto, p. 64.

${ }^{96}$ Obbligo e pretesa, p. 362.

${ }^{97}$ La fabbrica del diritto, p. 65.
} 
[...] che domani si vedrà opprimere a sua volta da una nuova minoranza di detentori del potere». ${ }^{98}$

La critica alla legislazione, che trova la sua fondamentale premessa teorica nella teoria del diritto come pretesa, fornisce la premessa analitica della proposta di riforma leoniana. Poiché lo strumento legislativo si rivela, nella maggior parte dei casi, strutturalmente inadatto a facilitare la registrazione delle pretese statisticamente giuridiche, occorre limitare il più possibile la produzione del diritto mediante l'impego della tecnica legislativa, e promuovere quelle tecniche produttive del diritto che consentano ai consumatori di regole giuridiche di «riprendere la loro vera funzione di produttori delle loro regole». ${ }^{99}$ In questa prospettiva, Leoni propone il recupero della centralità degli strumenti classici di produzione giuridica, quali le consuetudini, gli usi, i precedenti giudiziari, le opinioni dei giureconsulti.

\section{5.}

Chiariti i tratti essenziali della teoria leoniana del diritto, è ora utile mettere in luce quegli elementi di originalità teorica che rendono ancora oggi (a più di cinquant'anni dalla scomparsa di Leoni) gli scritti che qui si presentano meritevoli di lettura e approfondita riflessione. Senza pretesa di esaustività alcuna, e al solo fine di fornire al lettore alcune chiavi utili di comprensione, è possibile individuare tre fondamentali insegnamenti negli scritti di Leoni dedicati alla teoria del diritto; essi si collocano rispettivamente, sul piano epistemologico, strettamente giusfilosofico, e politico-istituzionale.

5.1. La prima lezione che può trarsi dall'impostazione teorica leoniana si colloca sul piano dell'epistemologia giuridica. Leoni ci mostra come l'individualismo metodologico radicato nello studio empirico delle azioni umane possa ambire a un carattere più scientifico e oggettivo, avalutativo e neutrale, che non alla pretesa oggettività degli approcci logico-formali al diritto. In altri termini, lo studio delle regolarità dei comportamenti individuali sul piano giuridico è in grado di fornire una base solidamente razionale per una conoscenza scientifica del fenomeno giuridico. È possibile apprezzare la ricchezza di quest'aspetto solo ove lo si colga nel contesto teorico che il filosofo torinese ebbe a riferimento negli anni della maturazione ed elaborazione della teoria della pretesa.

Il tema dello statuto epistemologico della scienza giuridica è al centro delle riflessioni di Leoni sin dalle prime opere giovanili degli anni ' $40 .{ }^{100}$ Risalgono a quel periodo due

\footnotetext{
${ }^{98}$ La fabbrica del diritto, p. 65.

${ }^{99}$ La fabbrica del diritto, p. 66.

${ }^{100}$ Bruno Leoni, "Il problema della scienza giuridica", in Memorie del- l'Istituto giuridico della $R$. Università di Torino, XLV, Torino 1940; Bruno Leoni, "Il valore della giurisprudenza e il pensiero di Julius von Kirchmann", in Rivista internazionale di Filosofia del diritto, n. VI, 1940, pp. 343-359; nn. I-II, 1941, pp. 64-65; Id., Per una teoria dell'irrazionale nel diritto, in "Memorie del- 1'Istituto giuridico della R. Università di Torino", vol. LI, Torino, 1942. Tali opere giovanili sono raccolte nel volume I di quest'opera. Cfr., per una ricostruzione critica: Alberto Febbrajo, "Il problema della scienza giuridica nelle opere giovanili di Bruno Leoni”, Il Politico, XXXIII, n. 3, 1968, pp. 621-629; Andrea Favaro, Bruno Leoni.
} 
monografie intitolate, rispettivamente, Il problema della scienza giuridica e Per una teoria dell'irrazionale nel diritto, oltre che un importante saggio intitolato Il valore della giurisprudenza e il pensiero di Julius von Kirchmann. In questi scritti si coglie già tutta l'esigenza leoniana di conseguire una conoscenza razionale e genuinamente scientifica del diritto. Tale esigenza connoterà l'intero percorso intellettuale del filosofo torinese. Tant'è che Giacomo Gavazzi affermerà che «la teoria della pretesa degli anni '60 rappresent[a] lo sforzo di realizzare proprio quel vecchio programma» ${ }^{101}$ già delineato nelle opere giovanili degli anni '40, riassumibile nello sforzo di saggiare la razionalità del diritto, evitando tanto il dogmatismo neokantiano che afferma quanto quello empirico che nega la razionalità della materia giuridica.

Dunque, è proprio negli scritti dedicati alla teoria della pretesa e alla critica del normativismo che l'epistemologia giuridica leoniana riesce ad articolarsi in una proposta metodologica più compiuta. In tali scritti emerge chiaramente il progetto leoniano di liberare le ambizioni scientifiche della scienza giuridica dallo sforzo di "purificazione" che caratterizzò il positivismo giuridico già a partire dagli ultimi decenni dell'Ottocento. Leoni si mostra consapevole del fatto che la garanzia di scientificità della scienza giuridica non possa rinvenirsi nella rimozione dall'indagine teorica di ogni riferimento ai comportamenti effettivi dei singoli individui. Lungi dal costituire una garanzia di scientificità del diritto, la separazione "neokantiana" del problema logico da quello fenomenologico finisce col deformare l'oggetto d'indagine della scienza giuridica, provocando numerosi inconvenienti (e arrecando ben pochi vantaggi) al teorico del diritto.

È utile osservare che sia Kelsen sia Leoni muovono da una dichiarata esigenza di avalutatività (Wertfreiheit) della scienza giuridica. ${ }^{102}$ Entrambi perseguono l'ideale di una conoscenza genuinamente "scientifica" del diritto e ravvisano nell'avalutatività dell'indagine giuridica la condicio sine qua non della scientificità del sapere. Tuttavia, il postulato dell'avalutatività porta $\mathrm{i}$ due autori in direzioni opposte. Per Kelsen, l'avalutatività si traduce in una tensione metodologica verso la "purezza", intesa come netta e rigorosa separazione tra "considerazione normativa" e "considerazione sociologica" del diritto. In un'opposta direzione, Leoni interpreta il postulato dell'avalutatività come l'esigenza di fondare la conoscenza giuridica proprio su considerazioni sociologiche, cioè sul dato empirico delle azioni dei singoli, delle relazioni interindividuali e dei risultati che ne conseguono. ${ }^{103}$

La divaricazione epistemologica tra l'impostazione kelseniana e leoniana si riflette nel differente modo di concepire il connotato aprioristico della conoscenza scientifica. Sia Kelsen sia Leoni ambiscono a individuare gli apriori di una teoria del diritto che ambisca

Dell'irrazionalità della legge per la spontaneità dell'ordinamento, Napoli, Edizioni Scientifiche Italiane, $2010^{2}$, pp. 17-80.

${ }^{101}$ Giacomo Gavazzi, "Conclusioni”, in AA.VV., "Il pensiero politico e giuridico di Bruno Leoni".

102 Bobbio coglie con grande lucidità questo punto: «Di fronte a un avversario accanito di Kelsen, come fu Leoni, non si può passar sotto silenzio che la Wertfreiheit fu anche uno dei caposaldi della teoria kelseniana, e lo fu proprio nel senso weberiano del rifiuto di ogni intrusione dei giudizi di valore nell'analisi dello scienziato»; Norberto Bobbio, "Bruno Leoni di fronte a Weber e a Kelsen", p. 133.

${ }^{103}$ Cfr. Bruno Leoni, "Riflessioni sul significato relativistico della Wertfreiheit nello studio dell'uomo," Il Politico, XLII, n. 4, 1977, pp. 625-638, pubblicato nel volume VII di quest'opera. 
a definire le condizioni generali di ogni ordine giuridico. Tuttavia, mentre l'atteggiamento neokantiano proprio del purismo kelseniano concepisce l'apriori come un concetto intellettivo puro, separato da ogni riferimento empirico all'esperienza sociale, l'atteggiamento leoniano colloca l'apriori nel contesto di un'analisi rigorosa del concreto agire umano. L'apriori kelseniano è una categoria trascendentale, una forma pura del pensiero. L'apriori leoniano è una categoria logica dell'agire umano concreto. Nell'impostazione leoniana, insomma, apriorismo ed empiria non appartengono a mondi separati, né corrispondono a metodologie conoscitive mutualmente escludentisi. Lungi dall'essere intellettualisticamente concepite, le costanti universali dei rapporti giuridici si manifestano come leggi della realtà, come regolarità statistiche.

È importante sottolineare che l'esigenza di valorizzazione delle cognizioni provenienti dall'esperienza non conduce Leoni sulla via di un empirismo ingenuamente naturalista di stampo positivista. Leoni è consapevole che il carattere scientifico dell'indagine sociale impone di commisurare il metodo di studio alla specificità dell'oggetto d'indagine. Egli rifiuta con fermezza l'idea di applicare il metodo delle scienze naturali al campo della ricerca sociale giuridica. ${ }^{104}$ Nello sforzo di conseguire una scienza rigorosa del diritto, Leoni rigetta sia il riduzionismo formalista-logicista sia quello positivista-naturalista e si muove alla ricerca di un approccio metodologico alla scienza giuridica che, evitando entrambi i riduzionismi, sia in grado di valorizzare tanto la conoscenza empirica dei fatti giuridici quando la conoscenza deduttiva che muova da precisi apriori.

Leoni individua un approccio all'altezza delle sue ambizioni metodologiche nell'ambito del quadro concettuale della Scuola austriaca dell'economia e in coerenza con il canone metodologico della sociologia comprendente weberiana. ${ }^{105}$ Una disamina dettagliata dell'influenza di questi referenti metodologici sulla teoria della pretesa esula dallo scopo di questo saggio introduttivo. ${ }^{106} \mathrm{E}$ tuttavia utile tratteggiare in maniera stilizzata quattro punti di collegamento tra la teoria della pretesa e, rispettivamente, l'individualismo metodologico mengeriano, la prasseologia misesiana, la sociologia del diritto ehrlichiana, e la sociologa comprendente weberiana.

Primo, la teoria della pretesa trasferisce nell'ambito del diritto la fondamentale intuizione mengeriana secondo cui gli «istituti sociali sono, nelle varie forme fenomeniche e nelle loro incessanti mutazioni, in non piccola parte il prodotto spontaneo dell'evoluzione sociale». ${ }^{107}$ In altri termini, la maggior parte dei fenomeni che sono oggetto di studio delle scienze sociali (diritto, linguaggio, moneta, mercato, ecc.) non sono esiti di piani intenzionali, quanto piuttosto il risultato del comporsi inintenzionale di conseguenze,

\footnotetext{
${ }^{104}$ Uno scritto assai significativo in tal senso è il seguente: Bruno Leoni - Eugenio Frola, "Possibilità di applicazione delle matematiche alle discipline economiche", Il Politico, XX, n.2, 1955, pp. 190-210.

${ }^{105} \mathrm{La}$ duplice radice austriaca e weberiana dell'impostazione leoniana è richiamata esplicitamente da Leoni. Ad esempio, nello scritto intitolato On a Recent Theory of Legal Obbligation, Leoni afferma: «in economy there are no "demands" without corresponding "supplies". But praxeologically (as Ludwig von Mises would say, or "pragmatically" as Max Weber would put it) the concept of "demand" is prior in economy just as well as the concept of "claim" (lato sensu) is prior in law».

${ }^{106}$ Un'accurata e assai ricca disamina dei referenti metodologici sottesi alla teoria leoniana della pretesa la si può trovare in Carlo Lottieri, Le Ragioni del diritto. Libertà individuale e ordine giuridico nel pensiero di Bruno Leoni, Soveria Mannelli, Rubbettino, 2006.

${ }^{107}$ Carl Menger, Il metodo nella scienza economica, Torino, Utet, 1937, p. 112 (enfasi aggiunta).
} 
anch'esse inintenzionali, di azioni umane intenzionali. ${ }^{108}$ La teoria della pretesa incorpora questo caposaldo dell'individualismo metodologico mengeriano e lo pone a fondamento della spiegazione dell'origine del diritto. Come illustrato in precedenza, l'analogia leoniana tra diritto e mercato e, in particolare, tra i processi formativi di norma giuridica e prezzo di mercato, ha proprio la funzione di porre in evidenza il carattere inintenzionale, spontaneo, del processo formativo del diritto.

Secondo, Leoni fa proprie, applicandole all'ambito giuridico, le istanze metodologiche della prasseologia misesiana. ${ }^{109}$ Come ha bene chiarito Lottieri, Leoni muove dalla premessa secondo cui « $[\mathrm{u}]$ na riflessione razionale sul diritto deve emulare quel tipo di conoscenze di portata generale che la prasseologia misesiana è riuscita ad individuare all'interno dell'economia». ${ }^{110}$ Leoni trova nella prasseologia misesiana quell'apparato metodologico che gli consente conseguire una conoscenza rigorosa e scientifica del diritto improntata al canone metodologico della Wertfreiheit. ${ }^{111}$ In Human Action, Ludwig von Mises elabora una teoria generale dell'azione umana basata su una serie di assiomi, concernenti sia la natura umana sia le interazioni intersoggettive, da cui egli ritiene di ricavare per via deduttiva una conoscenza rigorosa, razionale, certa dell'economia. ${ }^{112}$ La lettura di Human Action induce Leoni a convincersi che così come la scuola austriaca, sulle orme di von Mises, ha elaborato una teoria economica fondata su un'analisi razionale dell'azione umana, così la scienza giuridica deve elaborare un'analisi rigorosa dell'agire giuridico nello sforzo di cogliere le regolarità universali sottese a ogni ordine giuridico. Il cuore della prasseologia misesiana risiede dunque nell'individuazione di determinati apriori, cioè di regolarità universalmente valide che sottendono ogni ordine economico, da cui ricavare secondo un metodo rigorosamente deduttivo la spiegazione di tutta una serie di fenomeni economici. Che Leoni abbia inteso applicare questa metodologia all'ambito del diritto è evidente nelle pagine in cui indica quale compito della filosofia del diritto quello di «definire in che cosa consista l'azione giuridica nella sua completezza e [di] costruire [un] modello che consenta di "spiegare" il processo delle azioni giuridiche così come nella teoria economica si "spiega" il processo

\footnotetext{
108 Angelo Maria Petroni, "L'individualismo metodologico," in AA.VV., L'analisi della politica, a cura di A. Panebianco, Bologna, il Mulino, 1989; Lorenzo Infantino, L'ordine senza piano. Le ragioni dell'individualismo metodologico. Roma, Armando editore, 2008. Un'utile disamina critica dei punti di forza e dei limiti dell'individualismo metodologico la si può trovare in Dario Antiseri, Luciano Pellicani, L'individualismo metodologico. Una polemica sul mestiere dello scienziato sociale, Milano, Franco Angeli, 2005.

${ }^{109}$ Per cogliere il debito dell'impostazione leoniana verso l'impostazione metodologica misesiana, si veda la recensione di Bruno Leoni a Human Action di Von Mises, ora in Bruno Leoni, "Una recensione a Von Mises", in La sovranità del consumatore, Roma, Ideazione editrice, 1977, pp. 51-69. Una discussione critica di questo aspetto metodologico dell'opera leoniana la si trova in Adriano Gianturco Gulisano, "La 'teoria empirica' di Bruno Leoni. La centralità dell'approccio metodologico". Si veda anche, Frank Van Dun, "Bruno Leoni: Praxeology and the law", in Roberta Adelaide Modugno - Diana Thermes (a cura di), Bruno Leoni. Per un liberalismo integrale, pp. 80-110.

${ }^{110}$ Carlo Lottieri, "Prefazione" a Bruno Leoni, Lezioni di filosofia del diritto, p. 22.

${ }^{111}$ In Una recensione a Von Mises Leoni illustra come Human Action contenga «la scarna e robusta ossatura della teoria rigorosamente scientifica, e la consapevolezza della Wertfreiheit che è propria della scienza» (p. 61).

${ }^{112}$ Ludwig von Mises, Human Action, The Ludwig von Mises Institute, Auburn, 1988 (1949).
} 
delle azioni economiche». ${ }^{113}$ Ancora: «[u]na teoria del diritto che voglia essere esplicativa dovrà [...] anzitutto tener calcolo dei fini generalissimi [...] da cui è condizionata l'azione giuridica in ogni società di individui e dovrà tenere inoltre calcolo del rapporto intercorrente tra $\mathrm{i}$ fini ed i mezzi [...] che ogni singola società di individui avrà a disposizione per raggiungere quei fini»». ${ }^{114}$ Le pagine di Diritto e politica e Obbligo e pretesa in cui Leoni illustra l'analogia strutturale tra processo di formazione del prezzo di mercato e processo di formazione della norma giuridica vanno lette come un'applicazione del metodo prasseologico all'ambito giuridico. Leoni individua nell'incontro/scambio di pretese un preciso apriori del fenomeno giuridico - cioè una regolarità universale sottesa a ogni ordinamento giuridico. Da tale apriori egli ricava deduttivamente una serie di considerazioni concernenti i meccanismi di funzionamento dei processi istituzionali reali di produzione giuridica. Ad esempio, il dato universale dello scambio di pretese individuali offre le basi concettuali per spiegare l'inefficienza e l'incertezza generate dalla tecnica legislativa così come i vantaggi dei meccanismi evolutivi di produzione giuridica.

Terzo, il realismo empirico di Leoni fa capo alla tradizione della sociologia del diritto inaugurata da Eugen Ehrlich. Non v'è dubbio che il caposaldo teorico leoniano del radicamento del diritto nelle convinzioni e azioni dei singoli affondi le sue radici nella tesi centrale del fondatore della sociologia del diritto, secondo cui la scienza giuridica è scienza dei "fatti giuridici" e che pertanto «il centro di gravità dello sviluppo del diritto non si trova nella legislazione, né nella scienza giuridica, né nella giurisprudenza, ma nella società stessa». ${ }^{115}$ Da questo punto di vista, la polemica antikelseniana portata avanti dal Leoni può essere letta come l'ideale continuazione di quella vivace e famosa controversia teorica che si svolse tra Kelsen e Ehlirch sulle pagine dell'Archiv für Sozialwissenschaft und Sozialpolitik negli anni '10. ${ }^{116}$

Infine, Leoni si richiama espressamente ad alcuni fondamentali principi metodologici della sociologia weberiana. ${ }^{117}$ Il primo canone weberiano che Leoni ha costantemente a riferimento è il principio dell'avalutatività della scienza sociale. L'importanza che questo principio riveste nella riflessione del filosofo torinese è espressa a chiare lettere dallo stesso Leoni, ad esempio, in Terrore, Diritto e Costituzione, nel quale egli afferma: «Una "teoria" dovrebbe interessare tutti, e su un piano che non sia quello - squisitamente "privato" - delle loro emozioni: in questo senso io mi sento discepolo di Max Weber e fautore della sua teoria della "libertà dai valori" (che forse meglio si chiamerebbe: "libertà dalle valutazioni")». ${ }^{118}$ Il principio della Wertfreiheit si ricollega dunque

\footnotetext{
${ }^{113}$ A proposito della teoria del diritto e del positivismo giuridico, p. 226.

${ }_{114}^{114}$ A proposito della teoria del diritto e del positivismo giuridico, p. 231.

${ }^{115}$ Cfr. Bruno Leoni, "L'evoluzione del diritto e dell'economia", in Il diritto come pretesa, Macerata, Liberlibri, 2004, pp. 69-87, in particolare pp. 82-83. Si veda anche, Eugen Ehlrich, "Premessa dell'Autore", in I fondamenti della sociologia del diritto, Milano, Giuffrè, 1976.

${ }^{116}$ Hans Kelsen, "Eine Grundlegung der Rechtssoziologie", in Hans Kelsen - Eugen Ehrlich, Rechtssoziologie und Rechtswissenschaft. Eine Kontroverse (1915/1917), Baden-Baden, Nomos, 2003, pp. 3-54.

${ }^{117}$ Sull'influenza di Max Weber sulla concezione leoniana del diritto cfr. Alberto Febbrajo, "L'influenza di Max Weber sulla concezione leoniana del diritto come pretesa", pp. 155-167; Norberto Bobbio, "Bruno Leoni di fronte a Weber e Kelsen”, pp. 131-136.

${ }^{118}$ Terrore, Diritto e Costituzione, p. 298.
} 
direttamente all'esigenza, fortemente avvertita da Leoni, di una conoscenza rigorosamente razionale e genuinamente scientifica del diritto. Lottieri ha efficacemente illustrato questo punto come segue: «la difesa leoniana dell'avalutatività è pensata soprattutto a tutela della ragione umana: della possibilità di relazioni e dibattiti "razionali", indipendentemente dalle scelte personali e dagli orientamenti confessionali». ${ }^{119}$ Il secondo canone metodologico weberiano cui Leoni fa riferimento è quello della sociologia comprendente. Nelle Lezioni di filosofia del diritto, Leoni spiega il canone metodologico della "comprensione" (Verstehen) come segue: «Nello studiare i comportamenti bisogna cercare di comprenderli esaminando quale significato hanno per le persone che li hanno attuati». ${ }^{120} \mathrm{Si}$ tratta cioè di «riprodurre processi mentali che hanno condotto alla creazione di talune istituzioni». ${ }^{121}$ Una chiara applicazione della metodologia comprendente è data dalla ricerca del "minimo significato comune" attribuito alla parola "diritto" nei vari discorsi in cui tale termine è impiegato. ${ }^{122}$ In Obbligo e pretesa, Leoni osserva che il significato attributo dai parlanti alla parola "diritto" ha quale conseguenza il compimento di certe azioni. «Il nostro tentativo di comprendere quelle azioni diverrà dunque anzitutto un tentativo di comprendere $\mathrm{i}$ loro discorsi, e in questo tentativo, il "diritto" sarà precisamente né più né meno che una parola, impiegata nei loro discorsi ed il cui senso ci sforzeremo di comprendere. Questo tentativo di comprensione $\mathrm{dl}$ discorso diverrà il punto di partenza di ogni altro tentativo che faremo di comprendere che cosa il "diritto" sia e per parlarne a nostra volta». ${ }^{123}$

5.2. Un secondo importante insegnamento dell'opera leoniana si colloca sul piano strettamente giusfilosofico. Leoni mostra la possibilità di un pieno recupero, nell'ambito teorico del realismo giuridico empirista, dell'approccio giusfilosofico basato sull'idea di "natura della cosa", o "ratio naturalis". L'intreccio di empirismo sociologico e prasseologia misesiana, che come abbiamo visto caratterizza l'impostazione leoniana, consente di gettare le basi per una reinterpretazione su base empirica delle teorie del diritto naturale. In questo senso, può ben dirsi che la teoria della pretesa prepari il terreno per la formulazione teorica di un giusnaturalismo empirico. Questo aspetto è richiamato in modo esplicito nello scritto, assai significativo, intitolato Terrore, diritto, costituzione, come anche in A proposito della teoria del diritto e del positivismo giuridico e in Oscurità e incongruenze nella dottrina kelseniana del diritto. Ma procediamo con ordine.

L'impostazione leoniana è sicuramente realista perché valorizza la prospettiva empirica e psicologica al fine di conseguire la comprensione del fenomeno giuridico. ${ }^{124}$ Come si è visto, infatti, la teoria della pretesa radica la giuridicità delle norme nei comportamenti e negli atteggiamenti psicologici dei singoli che agiscono sul piano giuridico. La prospettiva empirista implica il rigetto del postulato formalistico per cui la conoscenza

\footnotetext{
${ }^{119}$ Cfr. ad esempio Carlo Lottieri, "Prefazione", in Bruno Leoni, Lezioni di filosofia del diritto, p. 30.

${ }^{120}$ Bruno Leoni, Lezioni di filosofia del diritto, pp. 260-261.

${ }^{121}$ Bruno Leoni, Lezioni di filosofia del diritto, p. 262.

${ }^{122}$ Cfr. Antonio Masala, Il liberalismo di Bruno Leoni, pp. 197-198.

${ }^{123}$ Obbligo e pretesa, p. 341.

${ }^{124}$ Cfr. Silvia Menocci, L'antiformalismo di Bruno Leoni nei suoi rapporti con le correnti del realismo giuridico.
} 
giuridica è intesa come un sistema di concetti puri; esso non è tuttavia incompatibile con l'ambizione a una conoscenza genuinamente scientifica del diritto. È proprio l'esigenza di un sapere oggettivo, certo e coerente che conduce Leoni a porsi in sintonia con la tradizione filosofica giusnaturalista. Infatti, la tradizione del diritto naturale esprime una tendenza verso la ricerca di contenuti giuridici universali, razionali, oggettivi che ben si coniuga con l'ambizione scientifica del diritto. Ma v'è di più. L'empirismo non è solo compatibile con l'esigenza di scientificità. Per Leoni, l'approccio empirico al diritto rappresenta il terreno previlegiato su cui reinterpretare e ricostruire la teoria del diritto naturale.

Leoni riconosce che ciò che allontana molte persone dal diritto naturale è «la mancanza [...] di convincenti dimostrazioni di tipo scientifico». ${ }^{125}$ Di conseguenza: «[d]alla crisi del concetto di "diritto positivo" come strumento di analisi teorica non deriva necessariamente un rafforzamento del vecchio concetto di "diritto naturale"». ${ }^{126} \mathrm{Per}$ Leoni, è necessario integrare la teoria del diritto naturale «con determinati contenuti empirici dotati di una generalità sufficiente a coprire la maggior parte delle società storiche a noi note». ${ }^{127}$ In altri termini: «Un riesame critico delle moderne dottrine sociologiche del diritto, condotto in parallelo con un approfondimento del significato empirico di talune dottrine classiche del giusnaturalismo classico potrebbe $[\ldots]$ costituire un notevole contributo alla ripresentazione di taluni degli antichi problemi del "diritto naturale" in una forma e con un significato accettabili al pensiero contemporaneo». ${ }^{128} \mathrm{E}$, infatti, plausibile che «[u]n simile modo di ragionare avrebbe un sufficiente grado di generalità per essere accettato come oggettivo e scientifico, senza invocare gli universali del giusnaturalismo metafisico vecchio stile». ${ }^{129}$

Nei passaggi sopra citati, Leoni intende spiegare che l'individuazione sul piano empirico di "costanti legali", cioè di contenuti giuridici che emergono con regolarità nel susseguirsi dei vari diritti storici, consente di identificare quelle condizioni generali cui qualsiasi ordine legale deve sottostare per funzionare. $\grave{E}$ cioè possibile enunciare generalizzazioni concernenti i contenuti del diritto che siano valide (nel senso di validità esplicativa) per ogni ordine giuridico. In questo senso, la prospettiva realista si collega all'idea centrale del giusnaturalismo classico - l'idea di una lex naturalis basata "sulla natura della cosa", sul "giusto per natura". ${ }^{130} \mathrm{Il}$ collegamento tra empirismo e giusnaturalismo è esplicito in Oscurità e incongruenze, ove Leoni afferma che «le contemporanee scuole sociologiche del diritto possono considerarsi $[\ldots]$ le "moderne eredi del diritto naturale"». ${ }^{131}$

\footnotetext{
${ }^{125}$ Terrore, diritto, costituzione, p. 299.

${ }^{126}$ Oscurità e incongruenze, p. 317.

${ }^{127}$ Terrore, diritto, costituzione, p. 299.

${ }^{128}$ Oscurità e incongruenze, p. 317.

${ }^{129}$ Terrore, diritto, costituzione, p. 300.

${ }^{130}$ Il filosofo torinese ebbe sempre a riferimento il tema della "natura della cosa", come dimostra la traduzione fatta dallo stesso Leoni, e apparsa nel 1941 sulla Rivista Internazionale di Filosofia del Diritto, dell'articolo di Gustavo Radbruch intitolato "La natura della cosa come forma giuridica di pensiero" (XXI, n. 3, pp. 145-156).

${ }^{131}$ Oscurità e incongruenze, p. 317.
} 
In questa particolare prospettiva è possibile leggere la teoria della pretesa proprio nel senso di una teorizzazione volta a porre le basi concettuali per una rifondazione in senso empirico della teoria del diritto naturale. Per comprendere come sia possibile una tale ambizione teorica occorre cogliere l'intreccio tra due distinte tecniche conoscitive - una deduttiva e l'altra induttiva.

Gli scritti leoniani sulla teoria della pretesa suggeriscono che la chiave metodologica per rifondare su basi empiriche il giusnaturalismo risieda proprio nel combinarsi di elementi conoscitivi a priori e a posteriori. Da un lato, la concezione del diritto come scambio di pretese implica la necessità di individuare per via empirica i contenuti universali propri del diritto naturale. Come si è visto, infatti, la distinzione tra pretese giuridiche e antigiuridiche è di tipo fattuale, basata cioè sulla probabilità statistica che una pretesa sia avanzata e soddisfatta in un determinato ambito storico. Se la giuridicità delle norme deriva dal convergere di pretese individuali statisticamente probabili, ne consegue che ogni indagine volta a individuare i contenuti universali del diritto non possa prescindere dallo studio empirico di quali siano le pretese statisticamente probabili emerse con regolarità nelle società storiche a noi note. V'è dunque un'operazione d'induzione dei contenuti giuridici che il teorico del diritto è chiamato a svolgere, sulla base di un esame dei rapporti giuridici concreti, storicamente determinatisi nel tempo, al fine di coglierne le regolarità sottostanti.

D'altro lato, Leoni è consapevole che l'accumulazione dei dati empirici non è di per sé sufficiente a fondare una conoscenza scientifica del diritto. Da coerente misesiano, Leoni è pienamente consapevole della distinzione tra storia e teoria, tra descrizione dei dati di fatto e riflessione teorica. Senza una spiegazione causale delle regolarità statistiche non può parlarsi di "legge" naturale, intesa quest'ultima come legge che identifichi le connessioni essenziali fra i fenomeni giuridici. Qui s'innesta il momento assiomatico deduttivo. Il costrutto teorico dello scambio di pretese - che costituisce un vero e proprio apriori - offre al teorico del diritto le basi concettuali per spiegare l'emersione delle regolarità giuridiche riscontrate sul piano empirico. Una volta che le regolarità giuridiche accertate empiricamente siano concettualizzate come "scambio di pretese individuali", la spiegazione causale di tali regolarità risiede necessariamente nell'analisi delle condizioni favorevoli al formarsi di un equilibrio tra pretese. In altri termini, se le "costanti legali" accertate empiricamente scaturiscono dalla convergenza di pretese, la spiegazione causale di tali "costanti" non potrà che riguardare quei giudizi tecnici e di valore posti in essere dagli individui che avanzano pretese statisticamente probabili. Lo studio dei rapporti tra $\mathrm{i}$ mezzi e fini dell'azione giuridica consente allora di spiegare il perché dell'emergere di determinate regolarità empiriche. La spiegazione del processo di formazione della "legge naturale" viene a coincidere con la spiegazione del processo delle "azioni giuridiche".

In sintesi, il teorico del diritto addiviene all'identificazione del diritto naturale attraverso 1) una paziente opera di accertamento empirico delle costanti giuridiche che hanno caratterizzato i vari diritti storici, e 2) una spiegazione assiomatico-deduttiva di tali

\footnotetext{
${ }^{132}$ Sul rapporto tra logica induttiva e logica deduttiva nella prasseologia giuridica leoniana, cfr. Carlo Lottieri, Le ragioni del diritto. Libertà individuale e ordine giuridico nel pensiero di Bruno Leoni, Soveria Mannelli, Rubbettino, specialmente pp. 51-64, 112-119, 147-165 e 344-352; Adriano Gianturco Gulisano, "La 'teoria empirica' di Bruno Leoni. La centralità dell'approccio metodologico".
} 
regolarità sulla base del modello dello scambio di pretese. Risulta sufficientemente chiaro come la teoria della pretesa, basata sull'intreccio tra induzione e deduzione, indichi la via verso la costruzione di un diritto naturale empiricamente fondato.

5.3. La terza lezione che può trarsi dall'impostazione leoniana si colloca sul piano della riflessione politica e istituzionale. Leoni sgancia sia il fondamento filosofico della produzione giuridica sia $i$ suoi meccanismi istituzionali dalla volontà dei detentori del potere politico, prospettando una concezione del diritto come ordine spontaneo senza costrizione. Quest'aspetto della filosofia del diritto di Leoni è al centro del celebre saggio La libertà e il diritto, nel quale Leoni elabora una critica serrata alla tecnica della legislazione unita a una strenua difesa degli ordinamenti giuridici di natura evolutiva e giurisprudenziale. Tuttavia, le tesi elaborate in La libertà e il diritto trovano le proprie premesse concettuali e filosofiche nella teoria del diritto come pretesa. Tale teoria fornisce una solida premessa logica al principio che il diritto è per sua natura indipendente dalla volontà dei governanti - principio su cui si fonda la polemica antilegislativa leoniana. In questa sede, non è possibile esaminare compiutamente la complessità e ricchezza di questo fondamentale plesso teorico, ma al solo fine d'illustrare le potenzialità critiche della teoria della pretesa è utile evidenziarne alcune importanti implicazioni sul terreno politico-istituzionale.

In primo luogo, come si è detto, la teoria del diritto come pretesa scardina l'idea che il diritto sia il prodotto conseguente della volontà del ceto politico. L'affermazione che le pretese individuali precedano logicamente le norme giuridiche e ne costituiscono al tempo stesso il fondamento esplicativo-causale conduce al superamento dell'idea che l'unico vero diritto sia quello posto, o imposto, dai detentori del potere politico: se la norma nasce dall'incontro e dallo scambio di pretese di singoli che agiscono sul piano giuridico, ne consegue che il processo di formazione del diritto sia in larga misura indipendente dalla sfera politica. Questa posizione consente a Leoni di identificare con grande lucidità le insidie insite nell'affermarsi di una concezione "politicizzata" della produzione giuridica. Leoni denuncia con vigore lo scivolamento dallo "stato di diritto" verso il monopolio del "diritto di stato", che ha progressivamente caratterizzato l'evoluzione giuridica delle democrazie europee continentali successivamente alla Rivoluzione Francese. Tale scivolamento verso il monopolio della produzione politica del diritto ha contribuito a trasformare il ruolo dello stato da "garante" dei diritti individuali a esso preesistenti a vero e proprio "fondatore" dell'ordinamento giuridico. La conseguenza di tale spostamento concettuale è quella di esporre i singoli individui che agiscono sul piano giuridico all'incertezza giuridica e all'arbitrio del potere politico. ${ }^{133}$

La teoria della pretesa scardina anche l'idea, ancor più fondamentale, che il diritto possa essere deliberato intenzionalmente - vale a dire, secondo il disegno finalistico di una volontà umana, individuale o collettiva. Secondo Leoni, il diritto emerge dall'incontro di pretese che si definiscono nella molteplicità delle interazioni individuali susseguentesi nel tempo. Pertanto, pur essendo radicato nelle azioni intenzionali e nei convincimenti di singoli individui che perseguono i propri fini particolari, il processo di

${ }^{133}$ Raimondo Cubeddu, Atlante del liberalismo, Roma, Ideazione editrice, 1997, p. 52. 
emersione delle pretese giuridiche è in larga misura inintenzionale, nel senso che nessuna singola azione individuale è, per sé sola, costitutiva del diritto, ma lo è soltanto nella misura in cui essa contribuisce sul piano fattuale al processo evolutivo del diritto. Così come nessun consumatore, individualmente considerato, è in grado di determinare il prezzo di mercato, così nessun attore giuridico, individualmente considerato, è in grado di determinare il contenuto delle norme giuridiche. Allo stesso tempo, il comportamento dell'insieme dei consumatori contribuisce in modo decisivo alla formazione del prezzo di mercato, analogamente a come il comportamento dell'insieme degli attori giuridici contribuisce alla formazione di norme giuridiche. Leoni compie, dunque, due passaggi teorici fondamentali sul piano della teoria delle fonti del diritto: da un lato egli rimpiazza un fondamento collettivistico con uno individualistico (decisioni individuali e non scelte collettive alla base della produzione giuridica); dall'altro egli sostituisce una razionalità evoluzionista a una di stampo costruttivistico (emersione inintenzionale invece che deliberazione razionale di norme).

$\mathrm{Su}$ tali premesse, la teoria della pretesa fornisce una ricostruzione concettuale del collegamento tra "autorità dei produttori di norme" e "volontà dei destinatari di tali norme" radicalmente alternativa alla teoria democratica. ${ }^{134}$ La teoria della pretesa pone, infatti, le premesse per una concezione della sovranità diversa dalla concezione democratica della sovranità popolare così come storicamente affermatasi nella cultura continentale europea. Nel contesto della teoria democratica il principio della sovranità popolare trova espressione istituzionale nel principio maggioritario e in quello della rappresentanza politica. In base a tali principi, la manifestazione giuridicamente rilevante della volontà popolare è affidata a una sequenza di scelte collettive basate sulla delega rappresentativa (dai governati ai governanti) e sulla regola della maggioranza (che disciplina i processi decisionali dei corpi legislativi e che è variamente qualificata a seconda dell'oggetto di decisione). Anche Leoni assume che la volontà dei destinatari delle regole giuridiche costituisca il fondamento della produzione giuridica; ma tale volontà non si esprime attraverso scelte collettive maggioritarie basate su procedure decisionali dal carattere imperativo, quanto, piuttosto, mediante un processo di formazione evolutiva di pretese statisticamente giuridiche. Per Leoni, la volontà che conta non è la volontà delle maggioranze rappresentative - le quali assai difficilmente sono in grado di registrare le pretese statisticamente probabili in un dato ambito storicosociale - ma piuttosto la volontà «che emerge dalla collaborazione di tutte le persone interessate, senza alcun ricorso a decisioni di gruppo e a gruppi di decisione». ${ }^{135}$ Tale è la "volontà comune" che si esprime nell'id quod plerumque accidit sul piano delle azioni e dei convincimenti giuridici individuali. ${ }^{136}$ Questo aspetto del pensiero leoniano acquisisce notevole importanza ove si ponga mente al fatto che Leoni scriveva, come ha efficacemente osservato Cubeddu, «in un momento storico in cui era diffusa e solida la

\footnotetext{
${ }^{134}$ Cfr. Roberta Adelaide Modugno, "Liberty Versus Democracy in Bruno Leoni and Friedrich Von Hayek", Libertarian Papers, 9, 2017, p. 233.

${ }^{135}$ Volume II, La liberta e il diritto, p. 2908 (corsivo dell'autore).

${ }^{136} \mathrm{Al}$ fondo di tale concezione v'è l'idea che la volontà degli individui sia meglio espressa da ciò che essi decidono o non decidono (cioè dalle pretese che essi avanzano) all'interno di una data società, piuttosto che per il tramite di rappresentanti (esponenti del ceto politico) che dichiarino di agire come loro agenti secondo la loro volontà.
} 
credenza che bastasse fondare il concetto di sovranità sul concetto di democrazia per rendere superflue le apprensioni circa i pericoli che un potere statuale illimitato avrebbe potuto rappresentare per il mantenimento delle libertà individuali»». ${ }^{137} \mathrm{~A}$ fronte di questo diffuso convincimento, la concezione leoniana del diritto fornisce un quadro concettuale che limita la sovranità politica delle maggioranze politico-parlamentari e che rende $\mathrm{i}$ diritti delle minoranze a esse indisponibili.

È emblematico in tal senso lo scritto intitolato Democrazia, socialismo e norma giuridica, nel quale Leoni pone enfasi sul principio per cui «molte norme giuridiche sono basate su presunzioni, ossia su ciò che i romani chiamarono id quod plerumque accidit, non solo nell'azione umana, ma anche nella mente umana». Il rispetto della minoranza in una comunità democratica è basato proprio «su una serie di presunzioni intorno a ordinamenti che la minoranza, in qualità di membro della comunità, non sarebbe disposta ad accettare». ${ }^{138}$ Il rispetto delle libertà di coloro che non appartengono alla maggioranza è garantito non dal «regno della norma giuridica astratta», ${ }^{139}$ il quale è in ultima analisi espressione di quelle stesse maggioranze politico-parlamentari, ma piuttosto dal riferimento a quei principi giuridici che sono espressione dell'id quod plerumque accidit e che possono essere considerati espressione della "comunità democratica considerata come un tutto». ${ }^{140} \mathrm{E}$ in tale volontà comune, piuttosto che nella decisione della maggioranza, che va radicato il fondamento delle libertà individuali. «[I]l sistema maggioritario è soltanto uno strumento, una sorta di inevitabile artifizio che non intacca il principio della comunità come un tutto». ${ }^{141}$ Ove le decisioni della maggioranza violino $\mathrm{i}$ diritti di libertà della minoranza, esse divengono illegittime, perché cessano di riflettere la volontà che è propria della comunità considerata come un tutto. Infatti «una minoranza che viene trattata alla stregua di un esercito sconfitto e sottoposto a un diktat da una maggioranza vittoriosa, non può più sentirsi parte della stessa comunità a cui appartiene la maggioranza». ${ }^{142}$

In Democrazia, socialismo e norma giuridica Leoni ripropone un tema che è presente nella sua riflessione teorica sin dalle opere giovanili. Di ciò offre testimonianza l'importante saggio intitolato Il concetto di "pubblica opinione”, apparso sulla Rivista di Filosofia nel 1946, nel quale Leoni evidenzia con chiarezza la distinzione tra i concetti di "pubblica opinione" e di "opinione della maggioranza". Scrive Leoni: «Pubblica è l'opinione della maggioranza, accettata da una minoranza che ha la libertà di esprimere il suo dissenso, ma che sente d'altra parte l'obbligo morale e politico di sottostare alla decisione dei più. In tutti i casi in cui la minoranza si ribella, o quantomeno non accetta l'opinione dei più, quest'ultima non è degna di chiamarsi pubblica». ${ }^{143} \mathrm{Il}$ "governo della comunità", basato sulla pubblica opinione, non va dunque confuso con il "governo della maggioranza", basato sulla sola manifestazione di una volontà maggioritaria in seno al

\footnotetext{
${ }^{137}$ Raimondo Cubeddu, "Il liberalismo di Bruno Leoni”, p. xviii (corsivo mio).

${ }^{138}$ Democrazia, socialismo e norma giuridica, pp. 548-549.

${ }^{139}$ Democrazia, socialismo e norma giuridica, p. 548. In La libertà e il diritto Leoni critica la fiducia riposta in Hayek nel principio di generalità e astrattezza delle leggi (si veda il volume II, p. 1650).

${ }^{140}$ Democrazia, socialismo e norma giuridica, p. 547.

${ }^{141}$ Democrazia, socialismo e norma giuridica, p. 547.

${ }^{142}$ Democrazia, socialismo e norma giuridica, p. 546.

${ }^{143}$ Il concetto di "pubblica opinione", p. 150.
} 
corpo elettorale. Mentre il governo della maggioranza conduce all'inesorabile soppressione della volontà del cittadino da parte dello Stato, il governo della pubblica opinione conduce all'adeguarsi del potere «alle volontà reali» di ciascun individuo. ${ }^{144}$ «La pubblica opinione non appartiene al meccanismo dello Stato: è un concetto estraneo a quelli che operano nel piano giuridico». ${ }^{145}$ La pubblica opinione fornisce un «canone di valutazione» dell'efficacia dello Stato democratico quale meccanismo portatore della volontà della comunità intesa come un tutto. Il meccanismo statuale basato sul concetto giuridico di governo del corpo elettorale, ed esprimentesi attraverso l'azione concreta degli organi costituzionali, non è in grado, per sua natura, di realizzare l'ideale democratico del governo della comunità come un tutto. Scrive Leoni: «[I]l fine dello stato democratico $[\ldots]$ cioè il governo della comunità come un tutto, non appare raggiunto coi mezzi di cui lo Stato storico dispone». ${ }^{146}$ Proprio questa inadeguatezza dello Stato democratico a perseguire il suo stesso fine ${ }^{147}$ spiega la funzione svolta dal concetto di opinione pubblica come tipo di una realtà che si contrappone al diritto delle costituzioni formali «come sfera che residua dal dominio di un'autorità esterna al volere dei singoli, e che non è traducibile nelle norme di quest'autorità». ${ }^{148}$

Può ben dirsi che nello scritto del '47 il concetto di "pubblica opinione" svolge una funzione di tipo normativo-valutativo assai simile a quella svolta dalla nozione dell'"id quod plerumque accidit" negli scritti della pretesa, così come quella svolta dalla nozione di "volontà comune" in La libertà e la legge. Pur nella differenza dei contesti analitici e nell'evolversi della prospettiva metodologica, il nucleo centrale della riflessione leoniana rimane quello di radicare il diritto nelle volontà individuali e di proteggere tali volontà dagli abusi di contingenti maggioranze politiche.

Sul terreno istituzionale, la teoria della pretesa pone le basi per una concezione puramente "descrittiva" (non, dunque, prescrittiva) dei meccanismi di produzione giuridica. Lungi dall'essere espressione di una volontà sovrana espressa da corpi collettivi ("popolo", "stato", "parlamento"), le fonti del diritto sono piuttosto concepite come strumenti di ricognizione e di applicazione di un diritto a essi preesistente. Su queste basi concettuali, la teoria della pretesa capovolge quella "presunzione di idoneità" della tecnica legislativa quale meccanismo di produzione del diritto, comunemente sottesa tanto al dibattito politico-istituzionale quanto ai processi reali di formazione delle politiche pubbliche. Leoni dimostra che la tecnica legislativa è uno strumento irrimediabilmente inadatto a registrare in modo efficiente le pretese statisticamente giuridiche. Ne consegue che il ricorso a tale tecnica debba essere respinto in qualsiasi situazione in cui la convergenza spontanea delle pretese conduca al raggiungimento di soluzioni giuridiche senza ricorrere a scelte collettive. ${ }^{149}$ In sostanza,

\footnotetext{
${ }^{144}$ Il concetto di "pubblica opinione”, p. 169.

${ }^{145}$ Il concetto di "pubblica opinione", p. 166.

${ }^{146}$ Il concetto di "pubblica opinione", p. 163.

${ }^{147}$ Leoni scrive, «lo stato democratico [...] non corrisponde interamente allo Stato democratico come concetto» (p. 164).

${ }^{148}$ Il concetto di "pubblica opinione", p. 168.

${ }^{149}$ Inoltre, l'approccio legislativo dovrebbe essere respinto quando esso sia utilizzato al solo scopo di imporre surrettiziamente pretese particolaristiche da parte di coloro che si trovano nella posizione di poter influenzare l'intero processo. Solo nei casi in cui la legislazione non sia respinta in conformità a tali
} 
la legislazione è chiamata a esercitare un ruolo sussidiario all'interno dell'organizzazione delle fonti del diritto, nei limitati casi in cui i meccanismi alternativi, spontanei ed evolutivi, di formazione del diritto non funzionino e sia dimostrabile che lo strumento legislativo possa avere successo là dove gli altri modi di produzione giuridica abbiano fallito. Si potrebbe dire - tracciando un parallelo con la teoria dello Stato minimo di Nozick - che Leoni elabori una teoria del "diritto a legislazione minima". ${ }^{150}$

Non stupisce, sulla base di tali premesse, che la concezione leoniana del diritto come pretesa implichi un rigetto della funzione del giudice come "produttore", o "creatore", di norme. Il giudice "scopre" e "descrive" i convincimenti giuridici diffusi nella società, e da questi ricava quelle generalizzazioni descrittive di pretese statisticamente rilevanti che si chiamano "norme". ${ }^{151}$ La regula da applicare per la soluzione di una controversia sottoposta all'esame dl giudice non è data, dunque, né da una norma legislativa, né dai personali convincimenti del singolo giudice circa le pretese meritevoli di protezione giuridica, ma piuttosto dalla ratio logica sottostante ai rapporti giuridici concreti. In altre parole, la ratio giuridica coincide con la logica economico-sociale sottesa al processo di formazione delle pretese staticamente rilevanti e, in quanto tale, essa è indisponibile tanto all'autorità giudiziaria quanto alla potestà legislativa del parlamento. Da questo punto di vista, sarebbero incompatibili con la concezione leoniana della funzione giudiziaria tanto la storica concezione del giudice come "bocca della legge", quanto tutta una serie di recenti trasformazioni subite dalla funzione giudiziaria che tendono a fare dei giudici dei veri e propri creatori di norme giuridiche. Si pensi, ad esempio, al crescente ruolo "politico" assunto dalle Corti Costituzionali, che in alcune giurisdizioni tendono a

principi, è possibile considerare se - date le specifiche circostanze di fatto - il processo legislativo possa godere di vantaggi relativi in termini di efficienza istituzionale rispetto alle altre fonti di produzione giuridica. Leoni scrive: «Sembra ovvio che dovremmo rigettare l'idea di ricorrere alla legislazione ogni volta che la si usi come mezzo per sottomettere minoranze allo scopo di trattarle come perdenti sul campo. Sembra anche indiscutibile che si debba rifiutare il processo legislativo ogni volta che gli individui coinvolti possano realizzare $i$ loro obiettivi senza dipendere dalla decisione di un gruppo e senza effettivamente costringere nessun altro a fare ciò che non avrebbe mai fatto senza costrizione. Risulta infine del tutto evidente che ogni volta che sorga un dubbio sulla desiderabilità del processo legislativo rispetto ad altro tipo di processo diretto a determinare le regole del nostro comportamento, l'adozione del processo legislativo dovrebbe essere l'esito di una valutazione molto accurata» (volume II, p. 788, corsivo dell'autore).

${ }^{150}$ Da questo punto di vista, chi scrive tende a leggere quelle affermazioni di Leoni volte a riconoscere un ruolo sussidiario alla legislazione meno criticamente di quanto fa un autorevole e perspicace studioso di Leoni come Lottieri, il quale invece ritiene di rinvenire un «atteggiamento poco rigoroso» nelle pagine in cui Leoni «nonostante le critiche che indirizza al diritto "costruito" dai legislatori [...] non arriva a negare ogni spazio alla legislazione»; Carlo Lottieri, Le ragioni del diritto. Libertà individuale e ordine giuridico nel pensiero di Bruno Leoni, p. 322. Diversamente, pare a chi scrive che quei passaggi di La libertà e il diritto non siano espressione di cedimenti intellettuali, quanto piuttosto affermazioni coerenti con un approccio metodologico basato sull'idea di un'analisi istituzionale comparata delle fonti di diritto. In base a tale approccio, ogni intervento legislativo dovrebbe essere preceduto e giustificato da una rigorosa analisi e dimostrazione sia dei fallimenti dei processi alternativi di produzione del diritto (consuetudini, evoluzione giurisprudenziale, ecc.), quanto dei vantaggi relativi, in termini di efficienza istituzionale, del ricorso alla tecnica legislativa. Ciò non porta a escludere radicalmente il ricorso alla tecnica legislativa, ma a ricondurre la legislazione a un ruolo sussidiario rispetto ai modi evolutivi e decentralizzati di produzione del diritto.

${ }^{151}$ Cfr. Bruno Leoni, "L'evoluzione del diritto e dell'economia", in Il diritto come pretesa, Macerata, Liberlibri, pp. 69-87, in particolare pp. 82-83. 
svolgere un vero e proprio ruolo d'indirizzo nei confronti del legislatore attraverso sentenze di tipo "paralegislativo". Ma si pensi anche alla recente tendenza, via via affermatasi nella giurisprudenza della Corte Suprema degli Stati Uniti, a incorporare i principi standard dell'analisi costi e benefici nell'ambito del sindacato giurisdizionale degli atti amministrativi, trasformando così il giudice in una sorta di "legislatore tecnocratizzato".

Infine, sulla base di quanto sopra discusso, non v'è chi non veda come la prospettiva analitica aperta dalla teoria della pretesa conduca a un ripensamento della nozione stessa di "costituzionalismo" nella direzione di una profonda valorizzazione di istanze di pluralismo giuridico. Coglie nel segno Cubeddu quando afferma che «l'insegnamento di Leoni è che la crisi dei sistemi democratico-liberali non può essere semplicisticamente risolta sottoponendoli a opportune cure di "ingegneria costituzionale"». ${ }^{152}$ Leoni immagina un ordine giuridico che non assomigli a una piramide ordinamentale politicizzata, ma sia piuttosto un ordine spontaneo che incarni l'ideale di una sovranità del diritto separata dall'arbitrio degli uomini. Da questo punto di vista la prospettiva leoaniana è radicalmente alternativa alle concezioni liberali novecentesche dell'ordine giuridico radicate in un impianto teorico contrattualista; si pensi, ad esempio, alla constitutional political economy di James Buchanan ${ }^{153}$ o alla teoria della giustizia di John Rawls. Pur nella loro diversità, tali concezioni concepiscono l'atto fondativo dell'ordinamento giuridico nei termini di una scelta collettiva (il contratto sociale), ispirata a un disegno di tipo finalistico, quale la massimizzazione dell'utilità individuale (Buchanan) o la realizzazione di principi di giustizia distributiva (Ralws). L'ordinamento giuridico che ne risulta appare necessariamente caratterizzato da un monopolio politico della produzione giuridica. Non si vedrebbe infatti quale forza prescrittiva potrebbe avere un contratto sociale dal cui ambito di applicazione rimarrebbe estranea parte della produzione giuridica. Tale prospettiva è del tutto incompatibile con l'idea leoniana per cui la più efficace protezione della libertà individuale risiede in un diritto radicato nelle azioni e nei convincimenti dei singoli. In tale concezione, il costituzionalismo non può che essere reinterpretato nel senso di una rule of law emergente da un ordinamento giuridico di tipo policentrico, organizzato secondo un principio di concorrenza istituzionale tra fonti del diritto. Le libertà individuali non sono garantite dal loro inserimento in strutture giuspubblicistiche o dalla messa a punto di determiniate tecniche costituzionalistiche, quanto piuttosto dalla policentricità dell'ordine giuridico dei privati.

\section{6.}

Chiariti gli elementi di originalità e fecondità teorica degli scritti leoniani dedicati alla teoria generale del diritto, è utile chiedersi sino a che punto Leoni sia riuscito nell'intento di elaborare una convincente teoria del diritto basata su di un rigoroso individualismo metodologico e che al tempo stesso sia pienamente coerente con il primato logico e assiologico della libertà individuale. Tale interrogativo ci aiuta a mettere in luce alcuni

\footnotetext{
${ }^{152}$ Raimondo Cubeddu, "Il liberalismo di Bruno Leoni”, p. xxxi.

${ }^{153}$ Per una critica agli assunti giuspositivisti sottesi al contrattualismo costituzionalista di James Buchanan, sia consentito di rimandare a Daniele Bertolini, “Constitutionalizing Leviathan: A Critique of Buchanan's Conception of Lawmaking”, in Homo Oeconomicus, 33, n.1, 2019.
} 
significativi elementi di debolezza dell'impostazione teorica leoniana e a individuare alcuni nodi teorici irrisolti cui potrebbero corrispondere utili ipotesi di ricerca futura. Nelle pagine che seguono si individuano tre elementi critici della teoria della pretesa: 1) l'ambiguità concettuale conseguente alla derivazione della giuridicità dalla probabilità statistica; 2) l'incompiutezza esplicativa della nozione di "scambio" di pretese; 3) l'unilateralità analitica con cui si affronta il tema del rapporto tra diritto e coercizione. Come si avrà cura di dimostrare, sotto questi tre profili, l'impostazione teorica leoniana si presta a potenziali risvolti anti-individualistici.

6.1. La teoria del diritto come pretesa sconta un primo fondamentale elemento di ambiguità con rispetto alla sua natura descrittiva o normativa. Leoni afferma, in più occasioni, che il proposito della teoria del diritto è quello di fornire una spiegazione logica e causale del fenomeno giuridico. Egli sembra dunque muoversi alla ricerca di un'oggettività di tipo descrittivo e avalutativo. Tuttavia, Leoni compie un passo ulteriore, che pare trascendere il piano puramente esplicativo-causale, quand'egli indica la probabilità statistica quale criterio pienamente idoneo al fine d'identificare le pretese giuridicamente rilevanti. L'impressione che l'analisi leoniana scivoli dal piano descrittivo a quello normativo si rafforza quando il filosofo torinese individua la nozione dell'id quod plerumque accidit quale criterio selettivo dei contenuti empirici del diritto naturale. Qui, la teoria della pretesa sembra tendere a un'oggettività di tipo normativo, cioè all'individuazione di contenuti universalmente validi che si pongano come surrogati dell'antico diritto naturale. ${ }^{154}$

In sintesi, mentre la tensione verso la scientificità del sapere giuridico conduce Leoni nella direzione di un'oggettività descrittiva, quella verso il recupero del diritto naturale sembra condurre il filosofo torinese verso la ricerca di un'oggettività normativa. Questa congiunzione di empirismo sociologico descrittivo e teoria normativa del diritto naturale espone Leoni all'obiezione di incorrere in una fallacia naturalistica, derivando il dover essere (del diritto naturale) dall'essere (delle pretese statisticamente probabili). ${ }^{155}$

\footnotetext{
${ }^{154}$ La tendenza alla normatività diviene manifesta in quei passaggi di La libertà e il diritto in cui Leoni ravvisa nell'id quod plerumeque accidit la manifestazione empirica di quella "volontà comune" che rappresenta il criterio normativo fondamentale cui ispirare il progetto leoniano di riorganizzazione delle fonti di produzione giuridica.

${ }^{155}$ Questo aspetto problematico del pensiero leoniano è stato colto da più parti; si veda, ad esempio, Juan Marcos de La Fuente, "Il diritto come pretesa e i rapporti tra diritto e politica", Rivista internazionale di filosofia del diritto, XXXVIII, 1961, pp. 441-444; Giacomo Gavazzi, "Conclusioni", in AA.VV., "Il pensiero politico e giuridico di Bruno Leoni", pp. 180-181; Mauro Barberis, "Diritto e legislazione. Rileggendo Leoni”, pp. 245-249. Si veda anche, James M. Buchanan, "Law and the Invisible Hand", in Freedom in constitutional contract, Austin, Texas A\&M University Press, 1977, pp. 25-39.

Sul rapporto tra l'idea di diritto naturale e il problema della fallacia naturalistica, si veda: Gaetano Carcaterra, Il problema della fallacia naturalistica. La derivazione dell'essere dal dovere essere, Milano, Giuffrè, 1969; Luigi Lombardi Vallauri, "Diritto naturale e diritto libero", Persona y Derecho, 23, 1990, p. 25; Francesco d'Agostino, "Il diritto naturale e la fallacia naturalistica", Persona y Derecho, 29, 1993, p. 181.

Sul rapporto tra evoluzionismo giuridico e fallacia naturalistica, si veda: Erik Angner, "Did Hayek Commit the Naturalistic Fallacy?", Journal of the History of Economic Thought, 26, n. 3, 2004, pp. 349-361; Bruce Caldwell - Julian Reiss, "Hayek, logic, and the naturalistic fallacy", Journal of the History of Economic
} 
L'obiezione della fallacia naturalistica, ancorché di per sé non insuperabile, indica la necessità di una più compiuta elaborazione del fondamento filosofico e metodologico del giusnaturalismo empirico. A giudizio di chi scrive, sia la posizione secondo la quale essere e dovere essere sono piani irrelati - e dunque qualsiasi passaggio inferenziale dall'essere al dover sarebbe precluso - che la posizione di chi afferma una relazione di immediata derivazione logica tra i due piani - posizione cui Leoni sembrerebbe a prima vista aderire - sono prive di solide fondamenta analitiche e concettuali. Da un lato, un appiattimento totale del dovere essere del diritto naturale sull'essere delle pretese statisticamente probabili finirebbe per tradursi, come ha efficacemente osservato Lottieri, «in una lettura meramente convenzionalistica della giustizia, viziata da un relativismo storico che rischia pure di convertirsi, in qualche circostanza, in un rigetto completo della prospettiva individualista». ${ }^{156}$ «Basti dire che in una società che mostri un'ampia accettazione verso condotte aggressive è possibile che finiscano per essere ritenute giuridiche regole tutt'altro che coerenti rispetto a un quadro liberale». ${ }^{157} \mathrm{D}$ 'altro lato, sarebbe eccessivo negare ogni rapporto tra essere e dovere essere. Tale posizione è oggetto di accese dispute sul piano filosofico e finirebbe dunque con lo sbarrare la strada, in modo forse affrettato, al progetto di una rifondazione empirica della teoria del diritto naturale. Un modo più utile di impostare il problema è di interrogarsi sul quando e in che misura sia analiticamente legittimo trarre dall'essere inferenze sul dover essere. Come Gaetano Carcaterra ha dimostrato, il passaggio inferenziale tra essere e dover essere non può trovare giustificazione sul piano della sola logica sottesa allo schema sillogistico; esso appartiene a un sistema filosofico più ampio, il quale solo può fornire i criteri di verifica della validità di tale inferenza. ${ }^{158}$

Sulla base di tali premesse, il superamento dell'obiezione della fallacia naturalistica nell'ambito della teoria leoniana richiede l'individuazione di criteri volti a discernere quando e in che misura sia legittimo trarre dall'essere dei concreti rapporti giuridici inferenze sul dover essere del diritto naturale. Leoni sembra avere intravisto questo percorso analitico quando - nello scritto intitolato A proposito della teoria del diritto $e$ del pensiero giuridico - egli risponde all'obiezione della fallacia naturalistica che Bobbio muove all'approccio basato sulla "natura della cosa". In tale contesto, Leoni ammette che l'esistenza di una regola non determina ancora necessariamente la scelta della stessa; tuttavia, egli puntualizza, in molti casi la distinzione tra esistenza di una regola e sua scelta non ha alcuna rilevanza pratica, perché la volontà di scegliere e applicare la regola

Though, 28, n. 3, 2006, pp. 359-370; Erik Angner, "Response to Caldwell and Reiss's 'Hayek, logic, and the naturalistic fallacy", Journal of the History of Economic Thought, 28, n. 3, 2006, pp. 371-373; Hendrik Gommer, "From the 'is' to the 'ought': A biological theory of law", Archiv für Rechts-und Sozialphilosphie, 96, n. 4, 2010, pp. 449-468; Enzo Di Nuoscio, "Liberi perché "ignoranti" e "ricchi" perché liberi. Per una difesa della libertà da una prospettiva evolutiva", Lessico di etica pubblica, 2, 2010, pp. 10-20.

${ }^{156}$ Carlo Lottieri, Le ragioni del diritto. Libertà individuale e ordine giuridico nel pensiero di Bruno Leoni, Soveria Mannelli, Rubbettino, p. 311.

${ }^{157}$ Carlo Lottieri, "Alle origini della teoria del diritto come pretesa individuale. Da Widar Cesarini Sforza a Bruno Leoni”, Materiali per una storia della cultura giuridica, 41, n. 1, 2011, p. 87.

${ }^{158}$ Cfr. Gaetano Carcaterra, Il problema della fallacia naturalistica. La derivazione dell'essere dal dovere essere, Milano, Giuffrè, 1969. 
è «facilmente presupponibile»e e «non ha quindi rilevanza il dubitarne». ${ }^{159}$ Solo nei casi in cui la volontà di adottare la regola non sia facilmente presumibile «la distinzione di Bobbio rimane non solo giustissima ma anche assai importante». ${ }^{160}$ Tali considerazioni sono certamente insufficienti a superare l'obiezione della fallacia naturalistica, ma paiono sufficienti a dimostrare che Leoni colga l'importanza di tale obiezione pur rimanendo convinto che, in molti casi, giudizi descrittivi e giudizi normativi, sebbene chiaramente distinguibili sul piano analitico, non siano del tutto separabili sul piano pratico.

Ogni ricerca che volesse proseguire, e attualizzare, il progetto giusfilosofico leoniano non potrebbe che cominciare con l'esaminare la fondamentale questione della derivabilità della giuridicità dalla mera probabilità statistica. Il chiarimento di questa questione consentirebbe di collocare la teoresi leoniana saldamente al riparo dai due opposti, ma egualmente sterili, estremi del formalismo purista ripiegato sul dover essere - e dell'empirismo positivista appiattito sull'essere.

6.2. Un secondo elemento di debolezza della teoria leoniana risiede, a giudizio di chi scrive, in un'incompiuta spiegazione del meccanismo causale sotteso allo scambio di pretese. Come ripetutamente discusso, Leoni formula un'analogia strutturale tra il diritto e l'economia e, in particolare, tra i processi formativi dei prezzi di mercato e quelli delle norme giuridiche. Tuttavia, una compiuta spiegazione causale del fenomeno giuridico dovrebbe poter dimostrare con precisione quali siano quelle dinamiche causali che sono all'opera nella formazione dei prezzi che occorrono anche nel processo di formazione delle norme giuridiche. Su questo punto, Leoni afferma un'analogia ma non la spiega. Non è dato ritrovare negli scritti leoniani dedicati alla teoria della pretesa una spiegazione compiuta di come, ad esempio, il meccanismo della domanda e dell'offerta - cui allude la metafora dello "scambio" - operi nell'ambito del diritto. Poiché non v'è dubbio che sussistano profonde differenze strutturali tra diritto ed economia, una compiuta spiegazione causale dell'origine del fenomeno giuridico non può permettersi di ignorare tali differenze, ma deve poter spiegare se e come tali differenze interferiscano, o interagiscano, con l'esplicarsi della dinamica dello scambio. ${ }^{161}$ Ciò nulla toglie al valore dell'illuminazione intellettuale prodotta dall'analogia leoniana; occorre però sottolineare che l'argomento analogico leoniano non soddisfa i requisiti di una compiuta spiegazione causale dell'origine del fenomeno giuridico. ${ }^{162}$

L'incompletezza esplicativa della teoria della pretesa genera una serie di problemi teorici assai rilevanti. Primo, manca nella teoria leoniana una spiegazione convincente del meccanismo e delle condizioni in virtù dei quali gli interessi dei singoli individui - e le pretese che da essi scaturiscono - trovino un punto di equilibrio in uno scambio di

\footnotetext{
${ }^{159}$ A proposito della teoria del diritto e del positivismo giuridico, p. 224.

${ }^{160}$ A proposito della teoria del diritto e del positivismo giuridico, p. 224.

${ }^{161}$ Per una critica al modello evoluzionistico basata sulle differenze strutturali tra diritto ed economia, si veda James M. Buchanan, "The limits of market efficiency”, Rationality, Markets, and Morals, 2, n. 38, 2011.

${ }^{162}$ I pregi e i limiti dell'analogia leoniana tra "scambio economico" e "scambio di pretese" sono discussi in Carlo Lottieri, "Exchanges, Claims, and Powers: About Bruno Leoni's Social Theory”, e nei commenti a esso releativi di Leeson, Stringham e Bouckaert.
} 
pretese, piuttosto che, ad esempio, nell'imposizione delle pretese mediante l'esercizio della forza, o financo nell'assenza tout court di qualsivoglia interazione. Secondo, anche assumendo che in un certo numero di casi le pretese individuali tendano a convergere verso situazioni di scambio, la teoria leoniana non pare in grado di spiegare perché lo scambio ripetuto nel tempo debba tendere verso l'emersione evolutiva di schemi giuridici di tipo privatistico piuttosto che verso strutture di diritto pubblico. Tale ultima ipotesi sarebbe altrettanto plausibile di quella leoniana incentrata sul diritto privato. Essa è, infatti, al centro di alcune ricostruzioni teoriche, nell'ambito della constitutional political economy, che tendono a spiegare l'emersione delle moderne architetture costituzionali come l'esito (efficiente) di scelte da parte di singoli tese a massimizzare la propria utilità individuale. Terzo, come Leoni stesso riconosce, «non c'è prova storica che sia mai esistita una situazione anarchica come quella che si avrebbe se la legislazione, le decisioni collettive e la coercizione delle scelte individuali fossero eliminate del tutto». ${ }^{163}$ Pertanto, una teoria compiutamente "esplicativa" del fenomeno giuridico non può esimersi dall'offrire la strumentazione concettuale atta a individuare le condizioni (ambientali o istituzionali) e i meccanismi in presenza dei quali lo scambio di pretese tenda a cristallizzarsi in norme di diritto privato piuttosto che in strutture di tipo giuspubblicistico.

La teoria leoniana sembra invece incapace di spiegare in modo convincente tanto il processo di formazione di equilibri cooperativi tra pretese quanto il formarsi di strutture e procedure decisionali di diritto pubblico. Da un lato, la teoria della pretesa rimuove in larga misura la coercizione dall'ambito privato, trascurando di non poco, sul piano analitico, l'evenienza che pretese irrimediabilmente confliggenti o comunque risultanti in esiti non cooperativi possano finire comunque col tradursi in istituzioni giuridiche (che dunque sarebbero ampiamente subottimali, ancorché evolutivamente generatisi). D'altro lato, la teoria della pretesa finisce col rigettare dal proprio campo di analisi il diritto pubblico, riducendo il diritto tout court a diritto privato. ${ }^{164}$ Ciò desta il sospetto che Leoni camuffi come "scambio" di pretese individuali una parte non irrilevante, e non eliminabile, del fenomeno giuridico che non sia in realtà riconducibile a un'origine di tipo privatistico-spontaneistico. Da questo punto di vista, si potrebbe dire che l'impostazione leoniana finisca col sostituire al riduzionismo kelseniano - del diritto a norma e della norma a obbligo - un riduzionismo di segno opposto - del diritto a diritto privato e del diritto privato a cooperazione spontanea.

L'assenza di una chiara ipotesi esplicativo-causale relativa allo scambio di pretese costituisce un importante limite dell'impostazione giusfilosofica leoniana anche perché finisce per indebolire la base concettuale su cui si regge la critica della legislazione. Poiché non è del tutto chiaro quali siano le condizioni in presenza delle quali l'incontro di pretese si cristallizzi in norme di diritto privato piuttosto che in istituzioni di diritto pubblico, la teoria normativa leoniana lascia scoperto un interrogativo cruciale. Se non può escludersi che le strutture giuspubblicistiche siano esse stesse l'esito evolutivo dell'incontro di pretese, su quale base può allora criticarsi la legislazione (come fa Leoni)

\footnotetext{
${ }^{163}$ Mauro Barberis, "Diritto e legislazione. Rileggendo Leoni”, p. 245.

${ }^{164}$ Mario Stoppino, "La grande dicotomia diritto privato - diritto pubblico e il pensiero di Bruno Leoni”, p. 122.
} 
affermando che essa distorce gravemente la realtà giuridica delle pretese comuni degli individui? ${ }^{165}$ Potrebbe ben darsi che il ricorso alla tecnica legislativa sia esso stesso il risultato di un percorso evolutivo originato dal confronto e incontro di pretese individuali. Pare dunque legittimo sospettare che la teoria della pretesa possa prestarsi, in una certa misura, a giustificare l'esistenza della legislazione o quantomeno di una certa quota di legislazione nell'ambito del sistema delle fonti.

La difficoltà che la teoria leoniana incontra nel fornire una risposta a tale interrogativo rivela sia la mancanza di una compiuta spiegazione causale della dinamica evolutiva sia l'assenza di precisi criteri normativi capaci di distinguere una "buona" evoluzione da una "cattiva" evoluzione. In altre parole, poiché non è chiaro come si verifichi l'evoluzione virtuosa verso norme di diritto privato, non è neppure chiaro quando tale evoluzione possa dirsi interrotta da intrusioni di tipo costruttivistico. Tale ultima determinazione richiederebbe di provare che nonostante la presenza (in un dato contesto storico) di circostanze favorevoli all'evoluzione di un efficiente ordine privato, una causa esterna al processo evolutivo ne abbia interrotto lo svolgersi. Ma va da sé che una simile prova presupporrebbe di poter conoscere e individuare con sufficiente precisione $\mathrm{i}$ fattori causali della dinamica evolutiva "virtuosa" verso un efficiente diritto dei privati. Fino a che la teoria della pretesa non sarà in grado di spiegare compiutamente il meccanismo dello scambio di pretese essa rimarrà incapace di supportare pienamente la pur illuminante critica leoniana alla legislazione.

Infine, anche qualora si potesse concludere che la legislazione sia imputabile a un'intrusione costruttivistica piuttosto che a un percorso evolutivo non se ne potrebbe automaticamente dedurre che essa rappresenti un'intrusione non desiderabile. Occorrerebbe, infatti, dimostrare che l'esito evolutivo di diritto privato sarebbe stato, nel singolo caso preso in considerazione, un esito che meglio riflette e registra il diritto vivente manifestantesi nella realtà delle pretese comuni. Valgono a tale riguardo le considerazioni svolte in precedenza circa l'obiezione della fallacia naturalistica.

6.3. Infine, un terzo aspetto problematico dell'impostazione leoniana concerne il rapporto tra diritto e coercizione. Come si è visto, l'analogia tra i processi formativi del diritto e del mercato costituisce il punto di partenza per un argomento squisitamente normativo, basato sulla critica alla legislazione e sulla conseguente difesa del diritto evolutivo. Leoni afferma che un ordinamento giuridico rispettoso del principio di libertà individuale dovrebbe rassomigliare il più possibile a un contesto di tipo concorrenziale sulla falsariga del libero mercato. Tale linea di pensiero si basa sulla premessa - chiarita in più parti negli scritti leoniani - che il mercato sia un contesto caratterizzato da scambi volontari, comportamenti cooperativi e, in definitiva, da assenza di coercizione; di converso, il processo politico-legislativo è un'arena istituzionale basata sul sistematico ricorso a decisioni di gruppo, gruppi di decisione, e procedure decisionali coercitive, nelle quali Leoni ravvisa l'operare sistematico di un principio di coercizione.

Tale linea argomentativa ha l'indubbio merito, lo si è sottolineato più volte, di mettere in luce i numerosi e gravi limiti della tecnica legislativa sotto il profilo del rispetto del

${ }^{165}$ Cfr. Mauro Barberis, “Diritto e legislazione. Rileggendo Leoni”, p. 248. 
principio di libertà. Tuttavia, a giudizio di chi scrive, la viva, per molti versi apprezzabile, tensione antistatalista che anima il pensiero leoniano porta il filosofo torinese a imprimere una "innecessaria" unilateralità analitica alla sua elaborazione teorica. In primo luogo, Leoni non sembra fare i conti con i numerosi punti di emersione - sul piano sia teorico che fattuale - di una relazione non sempre così lineare come egli pare assumere tra mercato e libertà individuale. Egli sembra trascurare completamente l'ipotesi teorica che i mercati non siano immuni da manipolazioni di singoli gruppi di potere o da violazioni private del principio di libertà individuale. ${ }^{166}$ Paiono cogliere nel segno le parole di Stoppino, il quale osserva: «Leoni concentrò la sua attenzione quasi esclusivamente sulla coercizione, che gli individui possono subire da parte del governo; mentre lasciò costantemente in ombra la coercizione, che individui o gruppi possono subire da parte di altri individui o gruppi, che non siano detentori del potere politico». ${ }^{167}$ In altri termini, nell'articolare la teoria della pretesa, Leoni sembra perdere di vista l'elemento coercitivo che connota in varia misura le interazioni umane nell'ambito privato $\mathrm{o}$, più in generale, al di fuori della sfera politico-istituzionale.

Quest'aspetto dell'analisi leoniana è il riflesso di un'opzione filosofica di fondo concernente il significato della nozione di libertà e, di conseguenza, della nozione di coercizione: Leoni attribuisce alla coercizione "privata" un valore diverso rispetto a quella "legale". Detto diversamente, Leoni nega che ciò che molti (anche da posizioni liberali) considererebbero come forme di coercizione sia in realtà qualificabili come tali. ${ }^{168}$ Tale duplicità di atteggiamento verso il tema della coercizione espone Leoni alle critiche di chi revoca in dubbio la stessa natura liberale del suo impianto filosofico. Tale tipo di critica è sintetizzata efficacemente nelle seguenti parole di Barberis riferite alla teoria leoniana della pretesa: «una teoria liberale della politica e del diritto [...] deve evidenziare la coercizione ovunque la trovi, e non limitarsi a denunciarla nei rapporti fra Stato e privati, ignorandola nei rapporti fra privati». ${ }^{169}$

La duplicità dell'atteggiamento leoniano verso la coercizione appare evidente, ad esempio, in Mito e realtà dei monopoli, in cui Leoni distingue tra monopolio legale e monopolio economico, negando legittimità al primo e riconoscendola al secondo. ${ }^{170} \mathrm{In}$ questo scritto Leoni riprende le tesi di Murray Rothbard sulla questione del monopolio così ravvisando un chiaro elemento coercitivo nel «monopolio imposto dal sovrano legale» ma negando che coercizione alcuna sussista nel caso del «monopolio cosiddetto economico». Il monopolio legale costituisce coercizione perché con la sua costituzione l'autorità politica viola la libertà di ciascun individuo di comprare, di vendere, e di

\footnotetext{
${ }^{166}$ Sul tema della "manipolazione di mercato" (market manipulation) si è sviluppata di recente una ricca letteratura giuridico economica. Cfr., ad esempio, Jon D. Hanson - Douglas A. Kysar, "Taking Behavioralism Seriously: The Problem of Market Manipulation", New York University Law Review, 74, 1999, p. 632; Ryan Calo, "Digital Market Manipulation", George Washington Law Review, 82, 2014, p. 995; George A. Akerlof - Robert J. Shiller, Phishing for Phools: The Economics of Manipulation and Deception, Princeton, Princeton University Press, 2015; Jamie Luguri - Lior Strahilevitz, "Shining a Light on Dark Patterns", University of Chicago, Public Law Working Paper, n. 719, 2019.

${ }^{167}$ Mario Stoppino, "La grande dicotomia diritto privato - diritto pubblico e il pensiero di Bruno Leoni", p. 130.

${ }^{168}$ Leoni illustra la sua concezione di libertà e di coercizione nel capitolo II di Diritto e Libertà.

${ }^{169}$ Mauro Barberis, "La teoria del diritto di Bruno Leoni”, p. 282.

${ }^{170}$ Bruno Leoni, “Mito e realtà dei monopoli”, Il Politico, XXX, n. 4, 1965, pp. 705-726.
} 
produrre ogni bene. Diversamente, il monopolio economico, costituisce una manifestazione pienamente legittima della libertà, che va riconosciuta a ciascuno produttore, di non vendere e di non produrre. ${ }^{171}$ Ogni legislazione volta a favorire la concorrenza e a contrastare la formazione o l'abuso di posizioni di monopolio privato è coercitiva nei confronti del produttore, perché ispirata, in definitiva, al principio «che il produttore sia il suddito del consumatore, e debba subire dunque le imposizioni sovrane [...] di quest'ultimo». ${ }^{172}$ Leoni afferma che «mentre non si pretende - di regola - che l'individuo in quanto consumatore compri beni ad ogni costo, si pretende invece che il produttore produca per così dire anche quando non vuole e gli si impone di concorrere anziché astenersi dal concorrere con gli altri produttori»». ${ }^{173}$

Non s'intende qui discutere il merito della critica leoniana alla legislazione antimonopolistica. Tuttavia, si vuole evidenziare come Leoni non sembri prendere in dovuta considerazione la differente posizione di forza in cui si trovano il produttore e il consumatore in numerosi mercati. Ciò porta la sua analisi (che per molti altri versi è utile e condivisibile) a perdere di vista alcune differenze strutturali tra il lato della domanda e quello dell'offerta di mercato che possono avere rilevanti implicazioni etico-normative. Ad esempio, Leoni pare trascurare il differenziale di costo tra azione collettiva dei produttori e quella dei consumatori in tutti quei casi (assai frequenti) in cui, mentre il potere del consumatore è esteso a una platea assai numerosa di individui il potere dei produttori è concentrato nelle mani di pochi attori e, di conseguenza, meno difficilmente "organizzabile" ai fini di eventuali azioni collettive. ${ }^{174}$ Ciò appare una differenza rilevante perché apre la possibilità a una spiegazione dell'inelasticità della domanda parzialmente diversa da quella offerta da Leoni. Mentre il filosofo torinese interpreta il gradiente di elasticità della domanda come il risultato di scelte dei consumatori, ${ }^{175}$ una maggiore attenzione al differenziale di costo dell'azione collettiva di produttori e consumatori illumina il vincolo cui i consumatori sono soggetti con rispetto alla possibilità di organizzarsi collettivamente per sottrarsi al potere di mercato del monopolista e così "elasticizzare", per così dire, la domanda. Naturalmente Leoni obietterebbe a tale considerazione che anche ove si considerasse il differenziale di costo dell'azione collettiva al fine di spiegare l'inelasticità della domanda, quest'ultima rinarrerebbe pur sempre l'esito di una libera scelta dei consumatori, i quali sono in fondo sempre liberi di scegliere altri prodotti o di collegarsi con altri consumatori per creare una nuova impresa produttrice di quei beni e così sottrarsi al rincaro monopolistico dei prezzi. Ma tale ipotetica contro-obiezione leoniana non farebbe che confermare il sospetto di una duplicità di atteggiamento verso il tema della coercizione. Anche i produttori, infatti, a fronte ai vincoli legali imposti dal sovrano hanno pur sempre la possibilità di scegliere un'attività diversa non sottoposta a restrizioni legali se non addirittura di cambiare

\footnotetext{
${ }^{171}$ Leoni giunge sino ad affermare che «[i]l monopolio imposto dal sovrano, o "monopolio legale" è l'unico tipo di "monopolio" definibile in modo rigoroso, e distinguibile in modo non equivoco da altri tipi di rapporto fra produttori e consumatori di beni» ("Mito e realtà dei monopoli", p. 705).

${ }^{172}$ Bruno Leoni, "Mito e realtà dei monopoli", p. 708.

${ }^{173}$ Bruno Leoni, "Mito e realtà dei monopoli”, pp. 708-709.

${ }^{174}$ Su questo aspetto si veda, ad esempio, James Buchanan, "The Relevance of Pareto Optimality", Journal of Conflict Resolution, 6, n. 4, 1962, pp. 341-354, in particolare p. 349-350.

${ }^{175}$ Bruno Leoni, "Mito e realtà dei monopoli", p. 713.
} 
giurisdizione. Ma Leoni è pronto a concludere che il monopolio legale violi la libertà dei produttori, mentre nega che il monopolio privato violi la libertà dei consumatori. La teoria della pretesa fatica a giustificare sul piano "scientifico" questa differenziazione, che appare motivata, in definitiva, da opzioni di tipo ideologico.

Leoni afferma che le legislazioni antitrust impongono al monopolista di concorrere e che così facendo esse finiscono per violare la libertà che va riconosciuta a ogni produttore di astenersi dal concorrere con gli altri produttori. Tuttavia, si può ben obiettare che al monopolista non si vieta affatto di astenersi dal "concorrere", ma solo di astenersi dal concorrere "negando la libertà di altri produttori di accedere al mercato". Leoni sembra non considerare il caso (anch'esso assai frequente nella pratica) in cui il produttore in posizione di monopolio impegni una parte significativa delle proprie risorse e strategie economiche non tanto nello sforzo di soddisfare le preferenze dei consumatori, quanto nel tentativo di escludere altri concorrenti dal mercato, cioè, in definitiva, di limitare la libertà degli altri produttori di produrre, di vendere e di commerciare e così di concorrere a soddisfare le attese dei consumatori. Egli sembra cioè assumere che l'unica modalità possibile di competere sul mercato sia quella di impegnarsi nell'offerta di beni che soddisfino le domande dei consumatori. Sulla base di questa premessa, egli sembra ritenere implausibile l'ipotesi che «i produttori tenderebbero, anziché massimizzare i propri profitti, soprattutto a danneggiare i consumatori, coltivando lo strano sport di rendere anelastica la domanda di questi ultimi». ${ }^{176}$ Sembra insomma che nel mercato leoniano non si dia l'evenienza di pratiche "abusive" di posizioni dominanti né di forme di esercizio di concorrenza "sleale". Per Leoni, quanto emerge dal mercato non è mai ingiusto, mentre quanto è deciso in via legislativa è sempre frutto di coercizione. Eppure, tali pratiche ostative del libero gioco della concorrenza ostacolano quell'incontro e quello scambio di pretese che la sua teoria erige a cifra genetica del diritto. ${ }^{177}$

Chiarita quella che, secondo chi scrive, rappresenta un'ingiustificata unilateralità analitica sul tema della coercizione, occorre chiarire che la messa in conto della coercizione privata non implicherebbe affatto l'abbandono del paradigma teorico della pretesa, quanto piuttosto un'accurata e conseguente analisi del rapporto tra pretesa e coercizione nei diversi contesti sociali e istituzionali. È convinzione di chi scrive che nel momento in cui Leoni individua lo scambio di pretese quale elemento fondante del diritto, egli fornisca una cornice analitica assai utile al fine di cogliere le differenze strutturali tra i differenti modi di produzione del diritto. Leoni spiega con grande acutezza come lo scambio di pretese - in cui si sostanzia l'essenza dl fenomeno giuridico - si esprima e si articoli diversamente, e con diversi gradi di efficienza, nelle diverse arene istituzionali. Nulla impedirebbe, pertanto, di sviluppare entro tale cornice analitica, un'analisi comparata delle varie forme di manifestazione della coercizione. Giova osservare, a tale fine, che Leoni individua quale elemento costitutivo della nozione di pretesa il potere di determinare il comportamento altrui da parte di chi esercita tale pretesa. Nulla osta, sotto il profilo teorico, a che s'includa in tale definizione il

\footnotetext{
${ }^{176}$ Bruno Leoni, "Mito e realtà dei monopoli", p. 719.

${ }^{177}$ Entrambe sono volte sì alla massimizzazione dei profitti, ma attraverso un'artificiosa limitazione della libertà economica di altri produttori tesa a generare una altrettanto artificiosa creazione di una domanda anelastica da parte dei consumatori.
} 
riconoscimento del fatto che, sotto determinate condizioni, il potere nei confronti del soggetto destinatario della pretesa possa tendere ad assumere forme di esercizio di tipo coercitivo - ciò pur in assenza del ricorso sistemico a decisioni di gruppo, gruppi di decisione o altre forme di coazione legale da parte dei soggetti che esercitano pretese. In breve, a giudizio di chi scrive, il paradigma concettuale della pretesa elaborato da Leoni contiene già in sé la potenzialità analitica per supportare una più compiuta e articolata indagine del rapporto coercizione/libertà individuale nelle diverse arene istituzionali. Tale modo di procedere non tradirebbe la tensione libertaria - talvolta financo fecondamente "anarchicheggiante" - ${ }^{178}$ sottesa all'impostazione leoaniana. Al contrario, essa esalterebbe il connotato libertario della teoria della pretesa, dotandola degli strumenti concettuali necessari per individuare la coercizione in qualunque arena istituzionale l'individuo si trovi ad agire.

Un breve esempio può essere utile a illustrare questo punto. Leoni critica severamente i meccanismi decisionali basati su "gruppi di decisione" e "decisioni di gruppo", poiché tali meccanismi finiscono coll'imporre a tutti i membri del gruppo decisioni che non riflettono propriamente la volontà di tutti i membri del gruppo; così facendo essi entrano irrimediabilmente in conflitto con la libertà individuale. Così, ad esempio, coloro che si trovano in minoranza in una decisione basata sulla regola della maggioranza finiscono per "sprecare" il proprio voto, ${ }^{179}$ giacché la loro volontà è contraddetta dalla decisione della maggioranza. Insomma, per Leoni la scelta collettiva «è sempre in ultima analisi suscettibile di venire applicata anche con la coazione a tutti i membri del gruppo, senza riguardo al loro particolare atteggiamento individuale verso la decisione stessa». ${ }^{180} \mathrm{~A}$ partire da queste considerazioni, Leoni giunge a esaltare le virtù dei processi giurisprudenziali evolutivi. Essi presenterebbero il vantaggio di meglio rappresentare la "volontà comune", intesa come volontà proveniente da parte di ogni membro della comunità. Tuttavia, questo passaggio comparativo nell'analisi leoniana è assai scivoloso ed è fonte di ambiguità concettuale. Infatti, il sistema evolutivo non dà all'individuo ciò che lamentabilmente la tecnica politico-legislativa gli toglie - vale a dire, la possibilità di incidere in modo effettivo sul contenuto delle regole collettive. Come ha messo bene in luce Febbrajo, l'impostazione leoniana «sottolinea il carattere interindividuale dei processi sociali e il carattere superindividuale dei loro esiti, che proprio in quanto prodotti dall'incrocio di volontà diverse giungono regolarmente a travalicare il concreto orizzonte del singolo individuo». ${ }^{181}$ L'impostazione leoniana finisce così per «appiattire il potere decisionale di ogni singolo individuo a quote infinitesime, proprio come avviene nel "tipo ideale" del mercato in condizioni di concorrenza perfetta». ${ }^{182}$ Quello di Leoni, insomma, è «l'individualismo dell'acquirente o del votante medio, attori questi essenziali ma per lo più inconsapevoli e, se presi singolarmente, assai poco influenti di meccanismi

\footnotetext{
${ }^{178}$ Mario Stoppino, "Introduzione" a Bruno Leoni, Le pretese e i poteri: le radici individuali del diritto e della politica, p. xxi.

${ }^{179}$ La fabbrica del diritto, p. 64.

${ }^{180}$ Approccio economicistico allo studio delle scelte politiche, p. 45 (enfasi aggiunta).

${ }^{181}$ Alberto Febbrajo, "L’influenza di Max Weber sulla concezione leoniana del diritto come pretesa", pp. 155-167, p. 164 (enfasi dell'ultima parte della frase aggiunta).

${ }^{182}$ Alberto Febbrajo, "L’influenza di Max Weber sulla concezione leoniana del diritto come pretesa", p. 165 .
} 
più grandi, potenti e "intelligenti" di loro, ai cui risultati ad essi non resta che conformarsi». ${ }^{183}$ Dunque, la lamentata mancanza di riguardo nei confronti delle volontà individuali da parte delle scelte collettive, pare connotare, sia pure in forma e misura diversa, anche i meccanismi evolutivi del diritto. ${ }^{184}$ Con ciò non si vuol negare la legittimità teorica del modello normativo leoniano, ma solo porre in evidenza che l'unilateralità analitica dell'analisi leoniana potrebbe essere utilmente integrata da una più rigorosa analisi comparata dei diversi meccanismi formativi del diritto. Non sfugge, infine, che un'integrazione della teoria della pretesa nel senso qui suggerito richiederebbe una più compiuta elaborazione teorica della coppia concettuale libertà/coercizione.

\footnotetext{
${ }^{183}$ Alberto Febbrajo, "L'influenza di Max Weber sulla concezione leoniana del diritto come pretesa", p. 165, n. 26 (enfasi aggiunta).

${ }^{184}$ Questo punto emerge, almeno in parte, nella parole di Carlo Lottieri quand'egli osserva che con «la nozione di scambio di pretese Leoni introduce ad un ordine giuridico in cui le opinioni predominanti (le pretese che hanno una più alta probabilità di essere avanzate e soddisfatte) riproducono tutte le difficoltà che sono caratteristiche dei regimi rappresentativi, su cui questo stesso autore ha scritto pagine molto critiche»; Carlo Lottieri, "Alle origini della teoria del diritto come pretesa individuale. Da Widar Cesarini Sforza a Bruno Leoni”, Materiali per una storia della cultura giuridica, 41, n. 1, 2011, p. 87 (enfasi aggiunta).
} 